\title{
Application of Distributed Optical Fiber Sensors for the Health Monitoring of two real structures in Barcelona
}

\author{
António Barrias ${ }^{1}$, Gerardo Rodriguez ${ }^{1}$, Joan R. Casas $^{1}$ \& Sergi Villalba ${ }^{2}$ \\ ${ }^{1}$ Technical University of Catalonia, UPC-BarcelonaTech. Department of Civil and \\ Environmental Engineering, c/ Jordi Girona 1-3, 08034 Barcelona, Spain \\ ${ }^{2}$ Technical University of Catalonia, UPC-BarcelonaTech. Department of Project and \\ Construction Engineering, c/ Colom 11, 08222 Terrassa, Spain
}

Corresponding author: Tel.: +34934016200 email: antonio.jose.de.sousa@upc.edu 


\section{ABSTRACT}

The versatility and easy installation of Distributed Optical Fiber Sensors (DOFS) compared with traditional monitoring systems is an important characteristic to consider when facing the Structural Health Monitoring (SHM) of real world structures. The DOFS used in this study provide continuous (in space) strain data along the optical fiber with high spatial resolution. The main issues and results of two different existing structures monitored with DOFS, are described in this paper. The main SHM results of the rehabilitation of an historical building used as hospital and the enlargement of a prestressed concrete bridge are presented. The results are obtained using a novel DOFS based on an Optical Backscattered Reflectometry (OBR) technique. The application of the optical fiber monitoring system to two different materials (masonry and concrete) provides also important insights on the great possibilities of this technique when monitoring existing structures. In fact, the influence in strain transfer between the DOFS and the bonding surface is one of the principal effects that should be considered in the application of the OBR technique to real structures. Also, and because structural surfaces generally present considerable roughness, the procedure to attach the optical fiber to the two monitored structures is described.

Keywords: structural health monitoring, optical fiber, distributed optical fiber sensors, Rayleigh backscatter, optical backscatter reflectometry.

\section{Introduction}

Civil engineering infrastructure has an extremely important role in the comfort, security and competitiveness of any society, enabling it to function properly. These structures however, are subjected to several events that deteriorate and compromise their structural integrity throughout their service lifetime. These events may adversely affect the future performance of infrastructures. In order to maintain and ensure the wellbeing of their users, it is paramount that the occurrence of damage in infrastructures is well followed and even predicted and controlled, enabling a fast action of condition screening that can minimize the adverse effects and inherent repair costs. Implementing such damage identification strategy for civil engineering infrastructure (as well as aerospace and 
mechanical engineering infrastructures) is indicated as Structural Health Monitoring (SHM) (Farrar \& Worden, 2007).

This has been one of the most studied and researched fields in the past two decades within the engineering and academic communities due to its vital importance and potential to allow better decision making by infrastructure owners and agencies. Nevertheless, there is still a lot of work to be done in order to practice SHM strategies in a large scale and in a systematic manner to civil infrastructures due to the current lack of reliable and inexpensive generic monitoring solutions (Glisic, Hubbell, Sigurdardottir, \& Yao, 2013).Traditionally, the assessment of the condition of buildings, bridges, tunnels and other vital civil engineering infrastructures, is carried out through periodical visual inspections by trained engineers, which sometimes can result in inaccurate evaluations due to the wide range of the background for safety condition assessment associated with each inspector.

The use of sensor-based monitoring systems improves SHM practices by improving their efficiency and accuracy, being here where the use of optical fiber sensors offers unmatched features. As it was already presented in various research papers (Casas \& Cruz, 2003; Ye, Su, \& Han, 2014), optical fiber sensors (OFS) present several advantages when compared to the more traditional and used electrical ones. Some of their most appealing characteristics are related with their immunity to electromagnetic interferences and corrosion, long term reliability and small size and weight (Lopez-Higuera, Rodriguez Cobo, Quintela Incera, \& Cobo, 2011; Todd, Johnson, \& Vohra, 2001). More specifically, the use of long-gauge fiber optic sensors combined with other standard sensors as accelerometers have shown their applicability in the damage detection in the case of a laboratory experiment. The use of fiber-optic sensors allows to overcome the difficulties associated with the traditional dynamic 
measurement methods, such as the limitations in the number and in the locations of the monitoring devices (Casciati et al. 2005 a,b)

Distributed Optical Fiber Sensors (DOFS) share the same advantages of discrete optical fiber sensors. However, contrary to the other sensors, they offer the possibility of monitoring variations of one-dimensional structural physical fields along the entire optical fiber in a truly distributed way. In this way, virtually every cross-section of the structure is instrumented. Furthermore, an additional benefit associated with distributed sensing is that it only requires a single connection cable in order to communicate the acquired data to the reading unit in opposition to the large number of otherwise required connecting cables when using discrete sensors. Hence, the installation and operation of distributed sensors is more simple and cost-effective (Glisic \& Inaudi, 2012).

The use of DOFS has opened new possibilities in structural tests and SHM due to its capabilities and versatility. There are three different processes of scattering that can be explored in a DOFS: Brillouin, Raman and Rayleigh scattering. Each scattering based technique has advantages and limitations, which makes that the decision to use any of them is directly correlated to its intended particular application.

The Raman scattering is significantly dependent of temperature effects. For this reason only some applications in civil engineering, as distributed temperature sensors in the detection of water leakage in dams and dikes, have been performed (Henault et al., 2010). Notwithstanding, this scattering technique has been used in a greater extent in the art restoration (Mayhew, Frano, Svoboda, \& Wustholz, 2014) and forensic fields (Muehlethaler, Leona, \& Lombardi, 2015).On the other hand, the Brillouin scattering based DOFS have found an extensive use in a wide range of applications to infrastructures, which makes it the most practiced technique in civil engineering SHM. This is due to its inherent characteristics which enables the use of this technique based 
sensors for long-distance distributed strain and temperature sensing which is favourable for large-scale applications of structural and geotechnical monitoring (Uchida, Levenberg, \& Klar, 2015). Nevertheless, its spatial resolution is considerably limited (around $1 \mathrm{~m}$ ) which consequently makes it not suitable for applications where damage detection is intended and in this way a higher spatial resolution is required. Some attempts have been made in order to improve this resolution to the level of centimeters (Belal \& Newson, 2011; Shen et al., 2010) which implies, however, greater computational and production costs.

The Optical Backscatter Reflectometry (OBR) is based on the Rayleigh backscattering Optical Frequency Domain Reflectometry (OFDR) which enables it to obtain strain and temperature measurements with high spatial resolution (Güemes, Fernández-López;, \& Soller, 2010; Rodriguez, Casas, \& Villalba, 2014). Although this implies also a limitation in terms of sensing length of around 70 m (LUNA, 2012), this technique allows the potential monitoring of different types of structures where it is possible to detect and locate, not only the premature emergence of cracks, but also their evolution and behaviour. The OBR technique, Figure 1, is composed by an active part

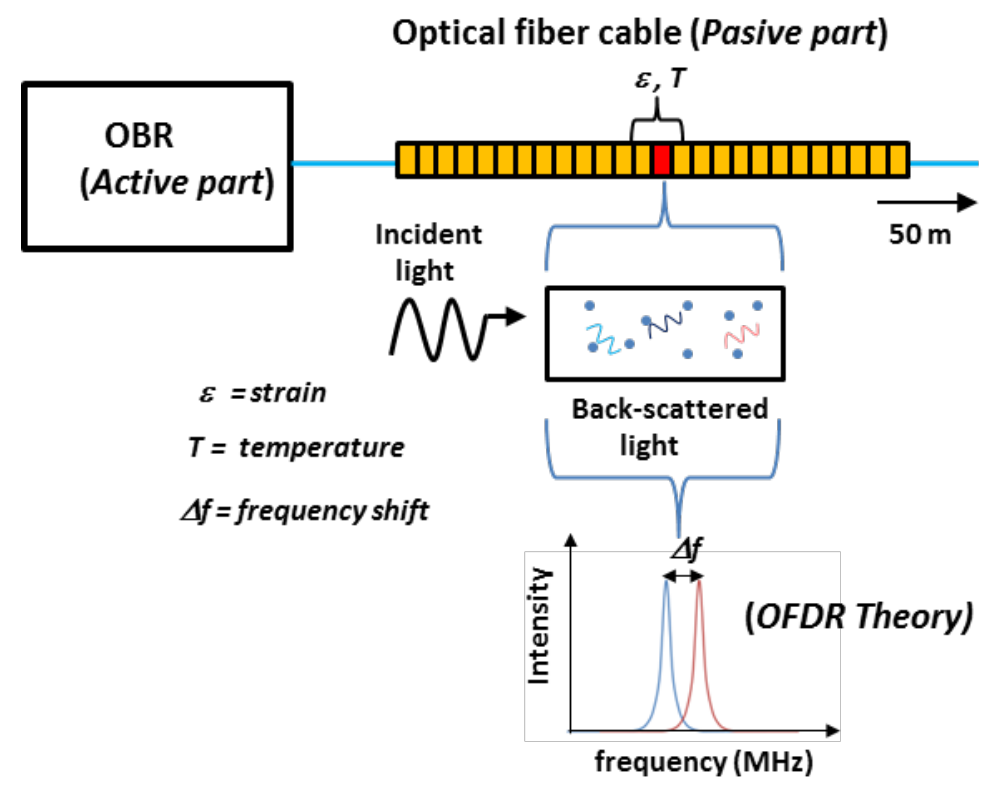

Figure 1. Measuring process by OBR system 
which sends a laser light through an optical fiber, and a passive part, where the light is reflected by the intrinsic variations along the fiber length (Samiec, 2012). This pattern of the reflections and the corresponding time of flight of the light is measured and stored, acting as a unique fingerprint for each fiber. When an external stimulus (like strain or temperature variation) happens, a temporal and spectral shift in the local Rayleigh backscatter pattern occurs. This new reflection pattern is then stored and compared with the original one providing through cross-correlation the variation and evolution of generated strains along the entire length of the fiber due to this external stimulus (Grave, Håheim, \& Echtermeyer, 2015).

This process uses the swept wavelength interferometry (SWI) to measure the Rayleigh backscatter as a function of length in an optical fiber with millimetre spatial resolution. More information on this system characteristics is also available in (Rodriguez et al. 2015a) and (Barrias, Casas, \& Villalba, 2016). Numerous works presenting information regarding the study of the potential of these sensors have been published in the last decade (Rodríguez et al. 2015 a,b; Palmieri \& Schenato 2013; Barrias et al. 2016), but very few showcase their application to real world structures. In this work, a step forward the application in the field is discussed as the application to two real structures is presented.

\section{Application to existing structures}

Although nowadays, there are others OBR systems with more setup functions and possibilities to measure using different types of fibers, the OBR model used in both cases of this study is limited to use a silica (glass) single mode fibers with a core diameter of $2 \mathrm{~mm}$ and a thin coating of polymer (polyimide) to protect it against scratches and environmental attack. Initially, this OBR system was created to measure strains and temperature variations in new components of aircraft and automobiles. 
Either at aircraft, automobile or civil structural monitoring, the principal reason to use a practically nude fiber is to optimally transfer the possible strain variation from the host material to the fiber core. Furthermore, although it is true that packaged fibers allow an easier manipulation and better protection of the fiber, an extra analysis of the strain transfer between the host material and the fiber is required to obtain the real strain variation in the monitored structure (Billon et al., 2014; Wan, Leung, \& Olson, 2008).

The OBR manufactures have provided a basic guide to DOFS installation (LUNA, 2017). This guide is focused on the implementation of DOFS onto a relatively smooth metallic or plastic surface at short lengths. In this way, for the implementation of these sensors in more fragile and rough materials, such as the ones showcased in this paper (masonry and concrete) the authors relied in other previous experiences where DOFS were installed in this type of materials (S. Villalba \& Casas, 2013; V. Villalba, Casas, \& Villalba, 2012).

Firstly, and in general form, a DOFS route was planned in order to measure strain at the locations and the directions of interest. The elected surfaces were prepared to develop a suitable bond area. These areas were cleaned with alcohol to free them from grease and facilitate the DOFS adhesion to the monitoring surface. The DOFS arrives from the manufacturer rolled on a spool. In general, the DOFS is strong in tension but weak in shear, therefore care needs to be taken in the installation to avoid its rupture. To prevent this, a carefully unwind of the DOFS from the spool is recommended followed by the attachment only using small adhesives dots, spaced at a maximum distance of $1 \mathrm{~m}$, to hold the DOFS in the planned route without any previous layer of adhesive on the monitoring surface. A view of this step of the sensor installation in the Sarajevo bridge, is shown in the Figure 2. 


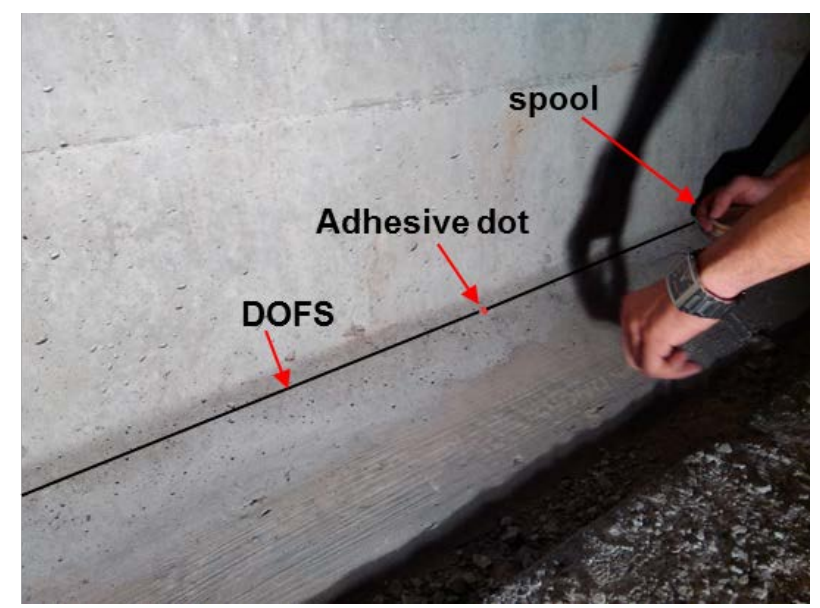

Figure 2. Unwind of the DOFS onto the chosen area of monitoring

Once the DOFS is laid on the structure's surface, the final step is to apply the epoxy adhesive to the DOFS and cure. A commercial glue as epoxy or cyanoacrylate could be applied to the bond area. About this, some authors (Regier \& Hoult, 2014), have shown that the installation of DOFS with of epoxy adhesives in concrete, produces better measures than using cyanoacrylate adhesives.

Therefore, a commercial bicomponent epoxy adhesive was applied to the bond area. A small brush to cover was used to cover the DOFS with epoxy avoiding to apply adhesive in excess (Rodriguez et al, 2015a). The bond thickness, amount of epoxy between the fiber and the surface, should be minimized to ensure that the fiber is truly resting on the surface of the monitored structure as shown in Figure 3, (LUNA, 2017). 


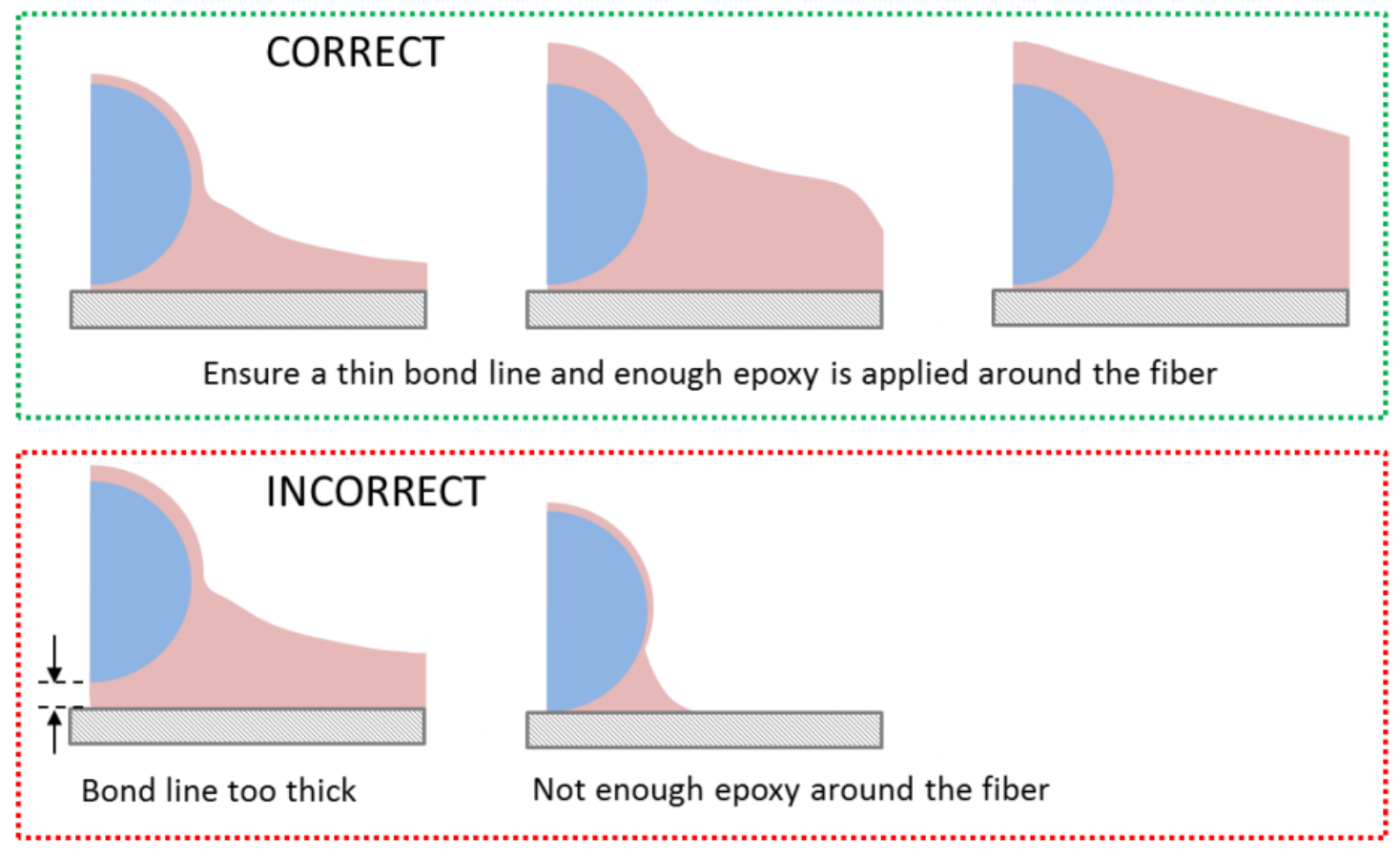

Figure 3. Adhesive application around the DOFS, (LUNA, 2017)

A general aspect of the sensor installation in the Sarajevo bridge is shown in Figure 4.
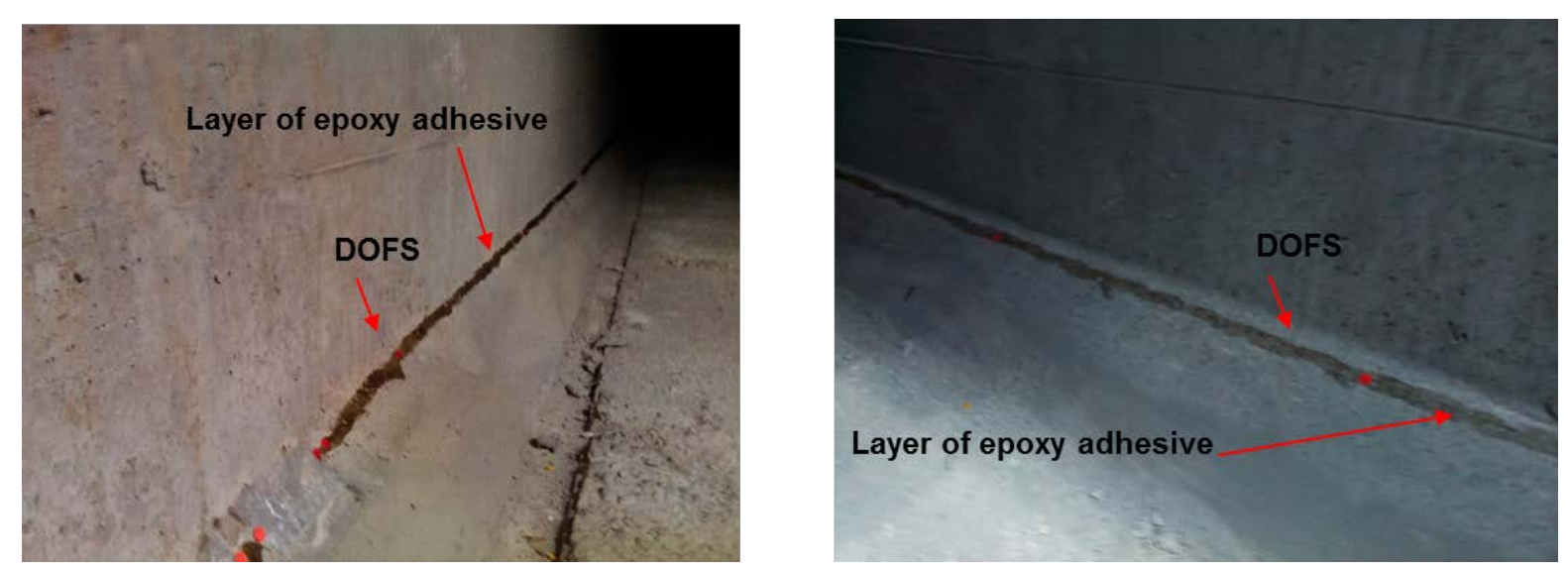

Figure 4. Final aspect of the sensor installation in Sarajevo Bridge

\subsection{Sant Pau Hospital}


This historical building and UNESCO world heritage site in Barcelona is an exquisite example of the Catalan architectural modernism movement (Figure 5). After many years in operation, some parts of the building presented some causes of concern related to its structural behaviour since some cracks were appearing in some brick masonry columns in one of the floors.

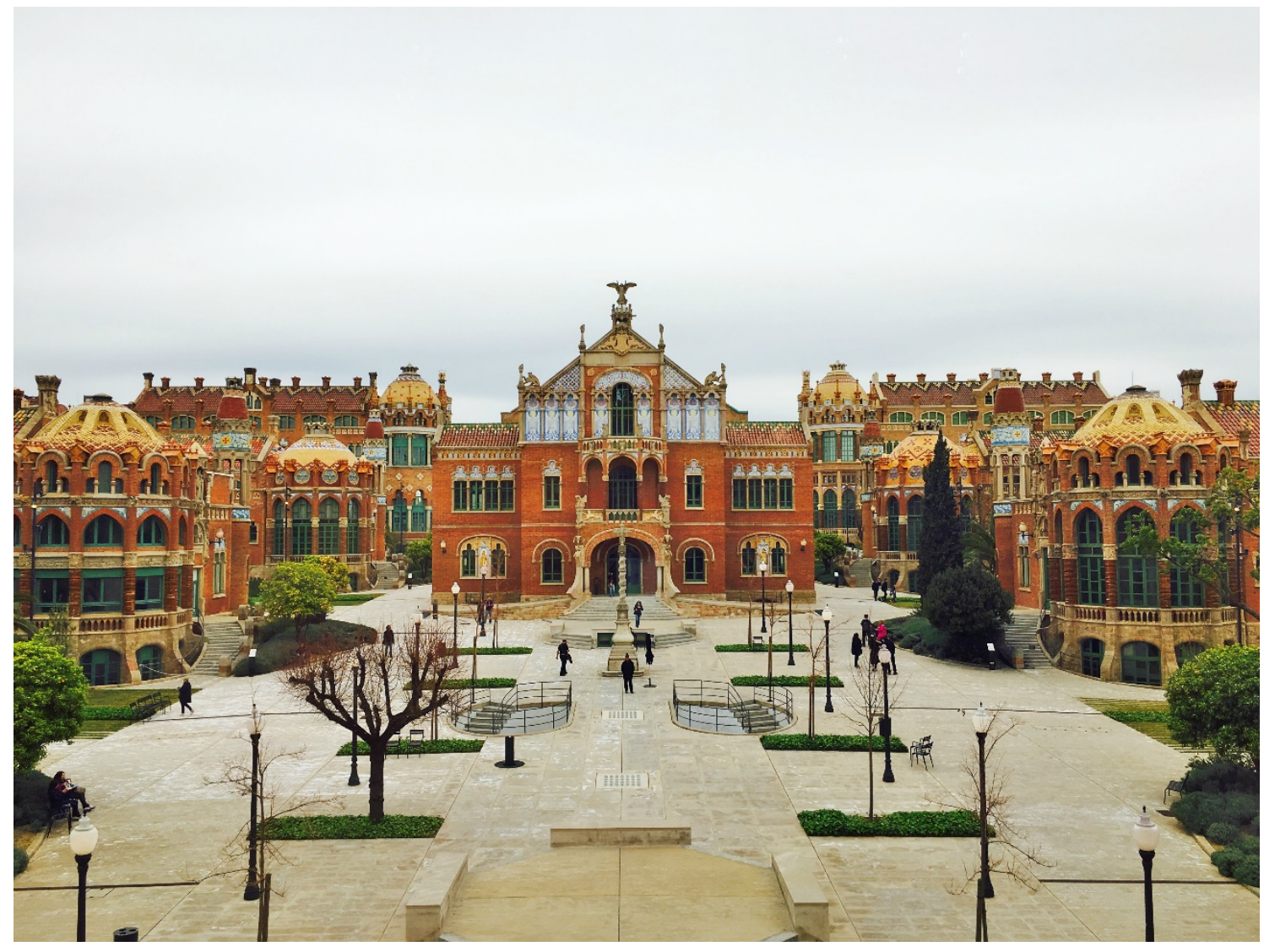

Figure 5. Sant Pau Hospital at Barcelona, Spain 


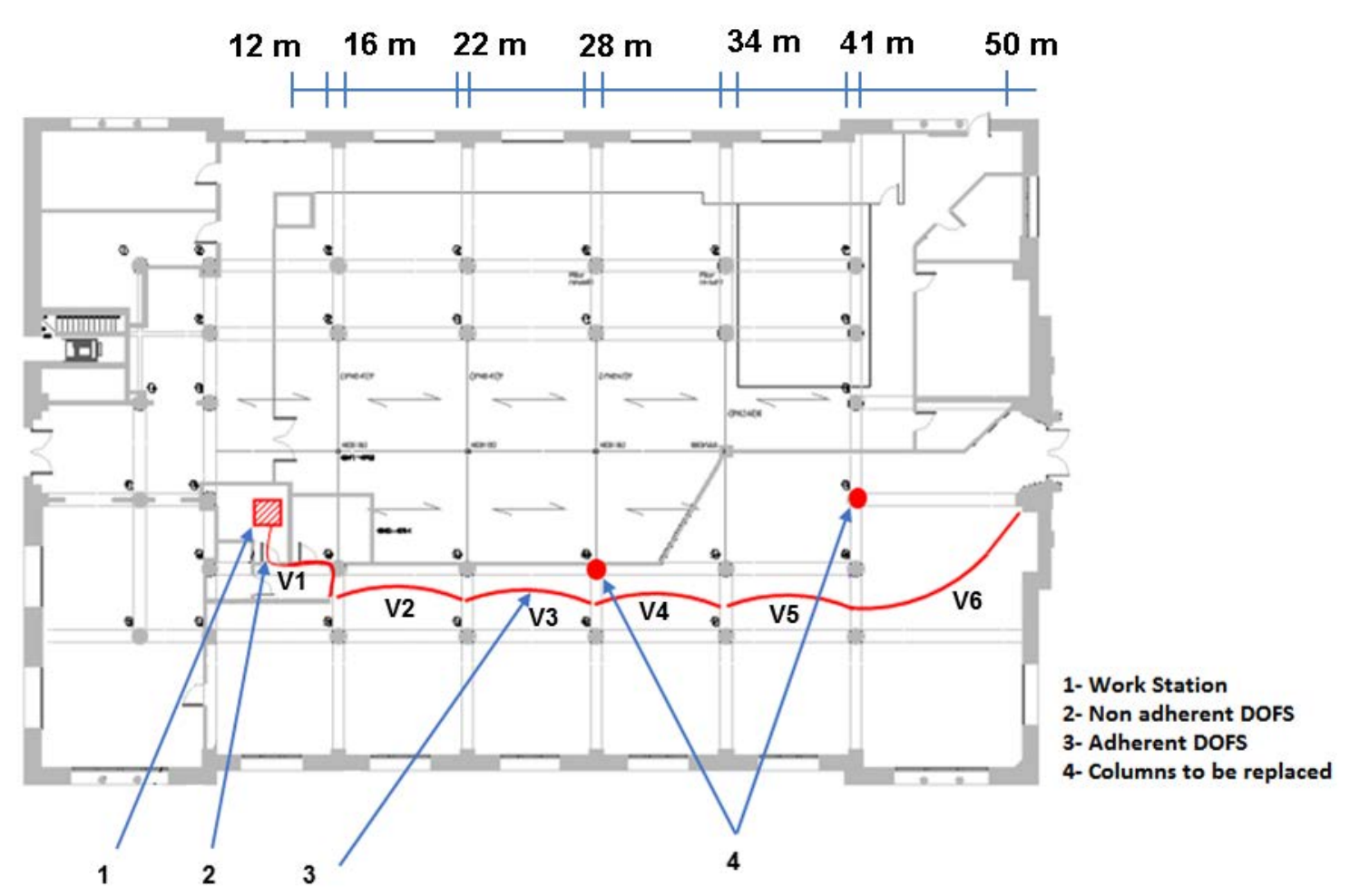

Figure 6. DOFS monitoring scheme. Plan view of the building

After a complete structural assessment, it was decided to replace two of those columns that were assessed to be working unsatisfactorily (represented as red circles in Figure 6) by new columns with steel as main structural material. The floor above was being used to accommodate recovery drug patients and their relocation during the restoration works was not an option. Therefore, it was mandatory to carry out the replacement/strengthening work with the building in full service. For this reason, a full structural monitoring was deemed as necessary during the rehabilitation works.

The replacement procedure consisted on implementing a steel structure surrounding the column to be replaced, just to transfer the load from the masonry column to this temporary bearing steel structure (see Figure 7 and Figure 9). Afterwards, the masonry columns were cut and removed (see Figure 8) and then replaced by definitive steel columns. The load was further transferred from the temporary bearing steel structure to the new column. These new members were then 
covered and protected with masonry elements in order to preserve the same architecture pattern as the remaining columns (see Figure 10).

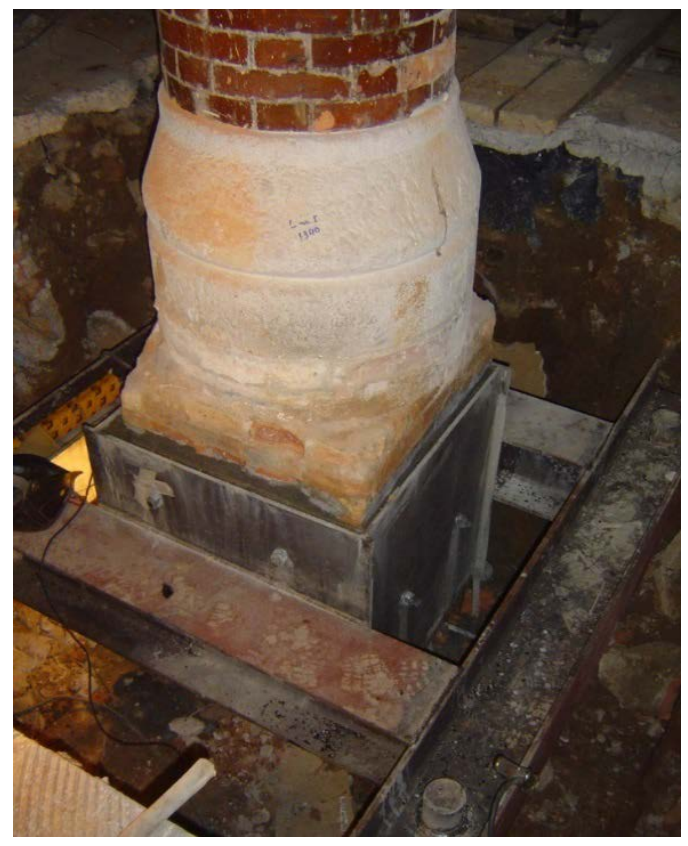

Figure 7. Preparation of columns to be replaced in this procedure

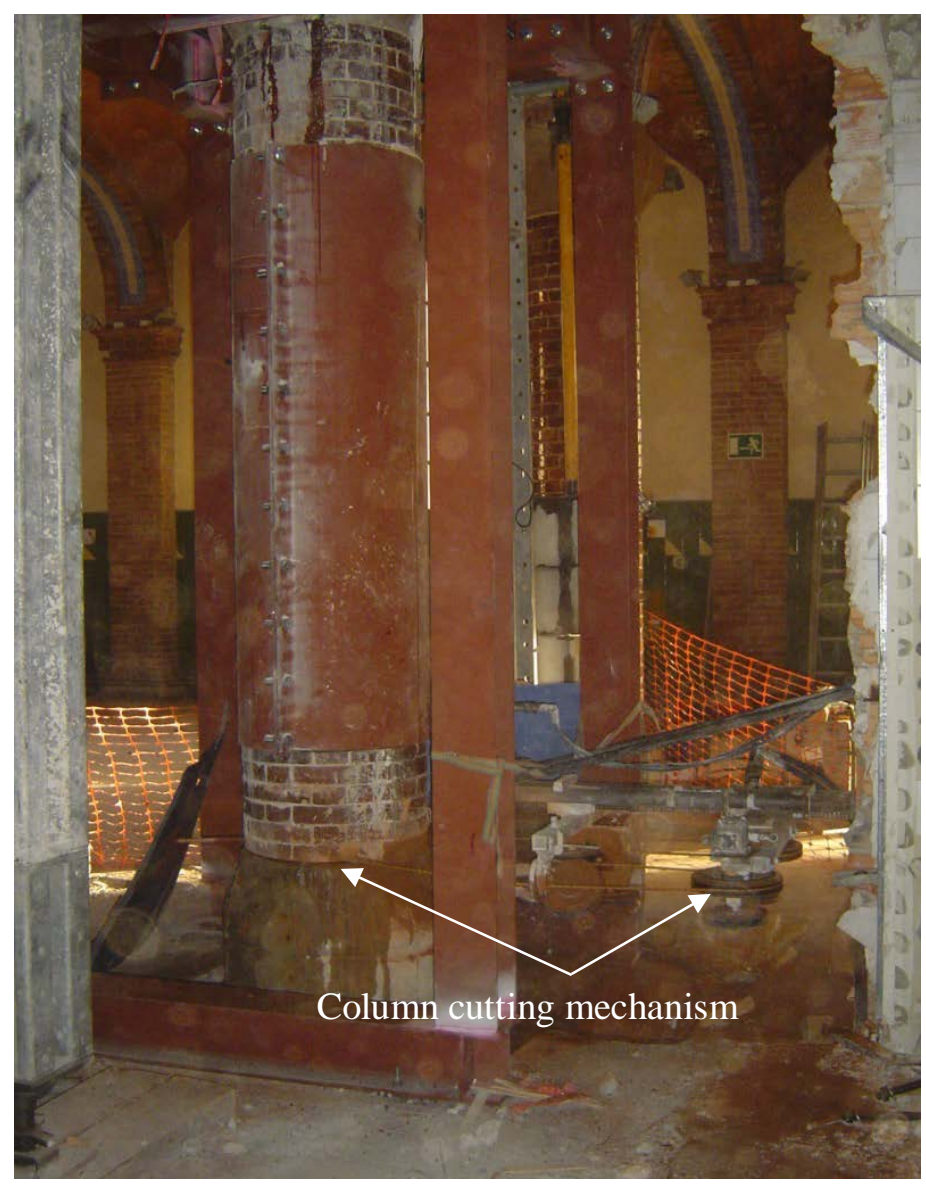

Figure 8. Cutting procedure of the columns 

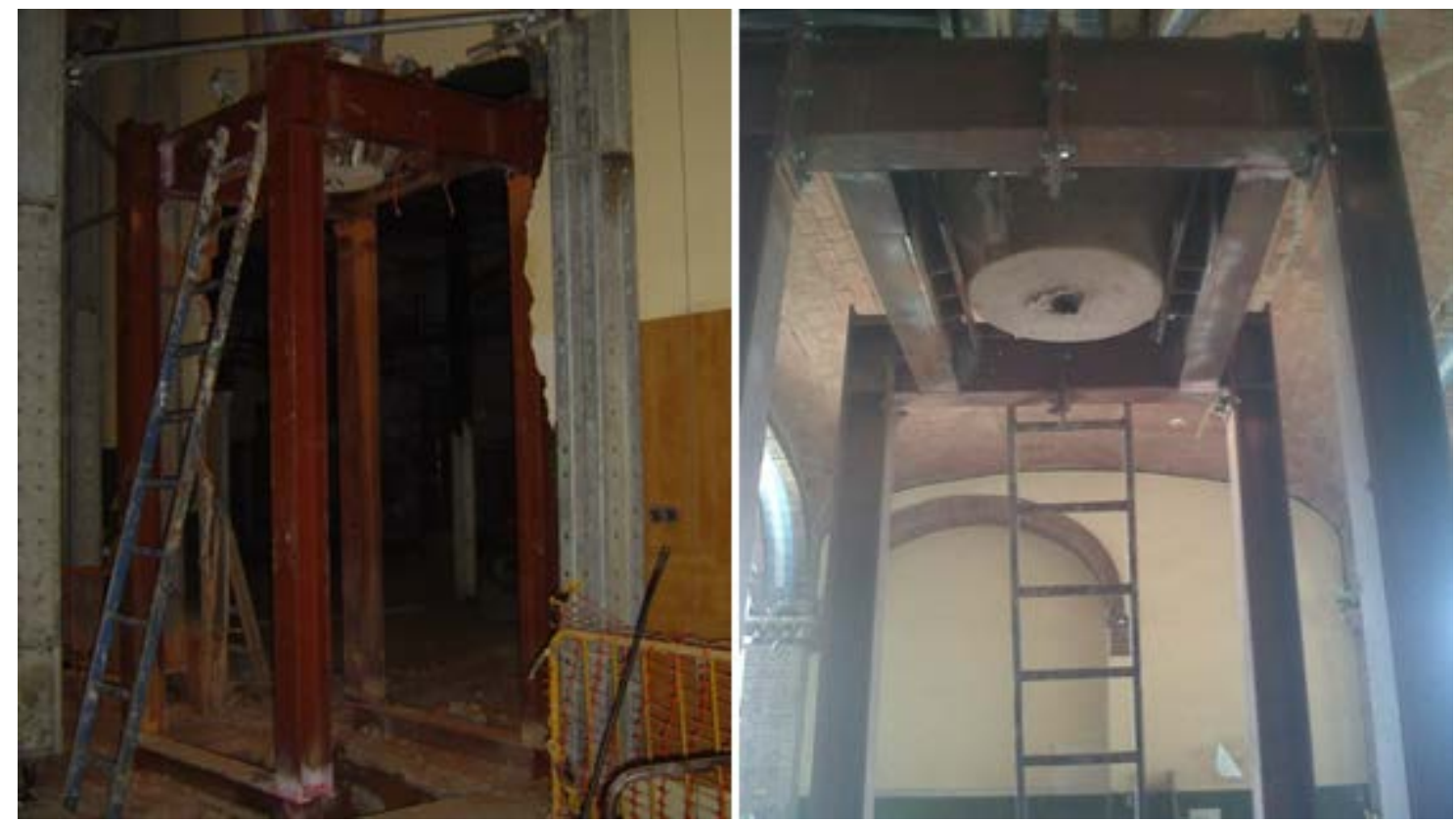

Figure 9. Temporary steel frame installed close to the columns to be replaced
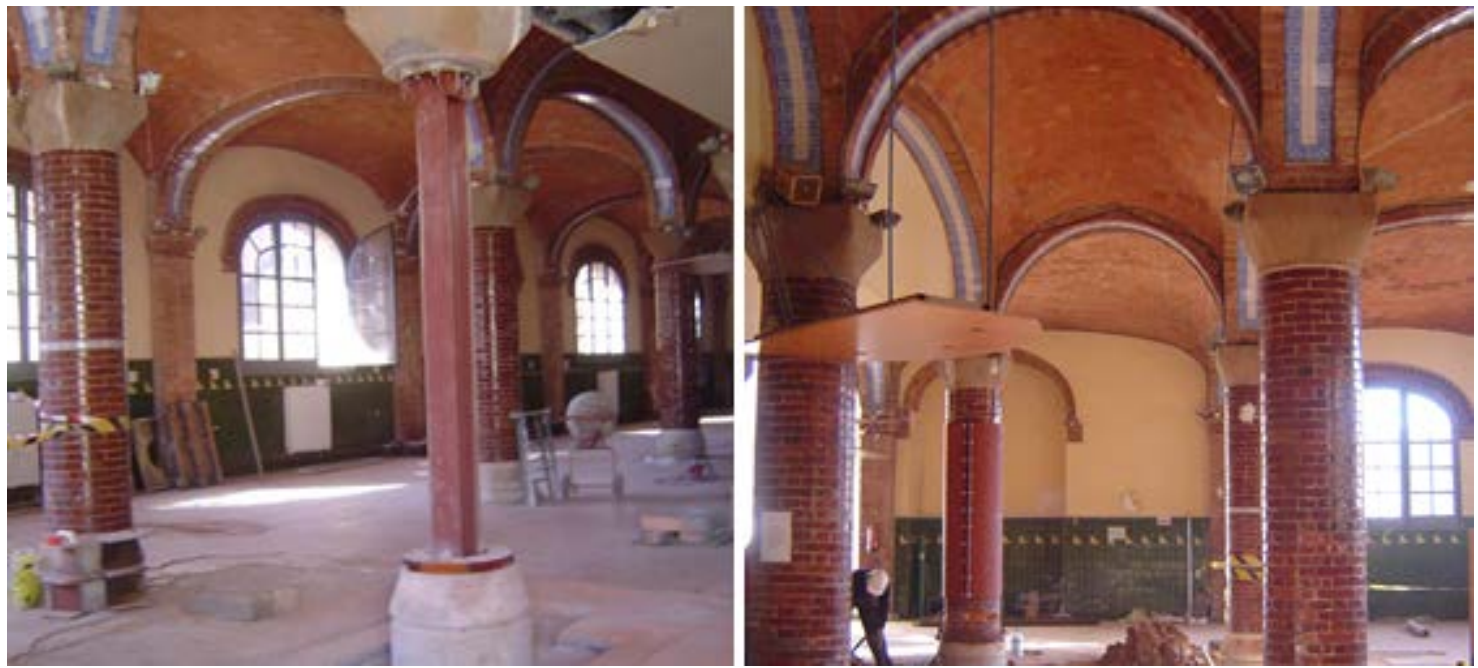

Figure 10. Final works. Implementation of steel profiles and following encapsulation

Because of this challenging process, that had to maintain the hospital in full operation, it was decided to implement a system that could monitor continuously (both in time and space) the structural behaviour during the column replacement process. In this way, any deviation from a normal structural performance could be detected, the warning processed and the posterior operations decided. 

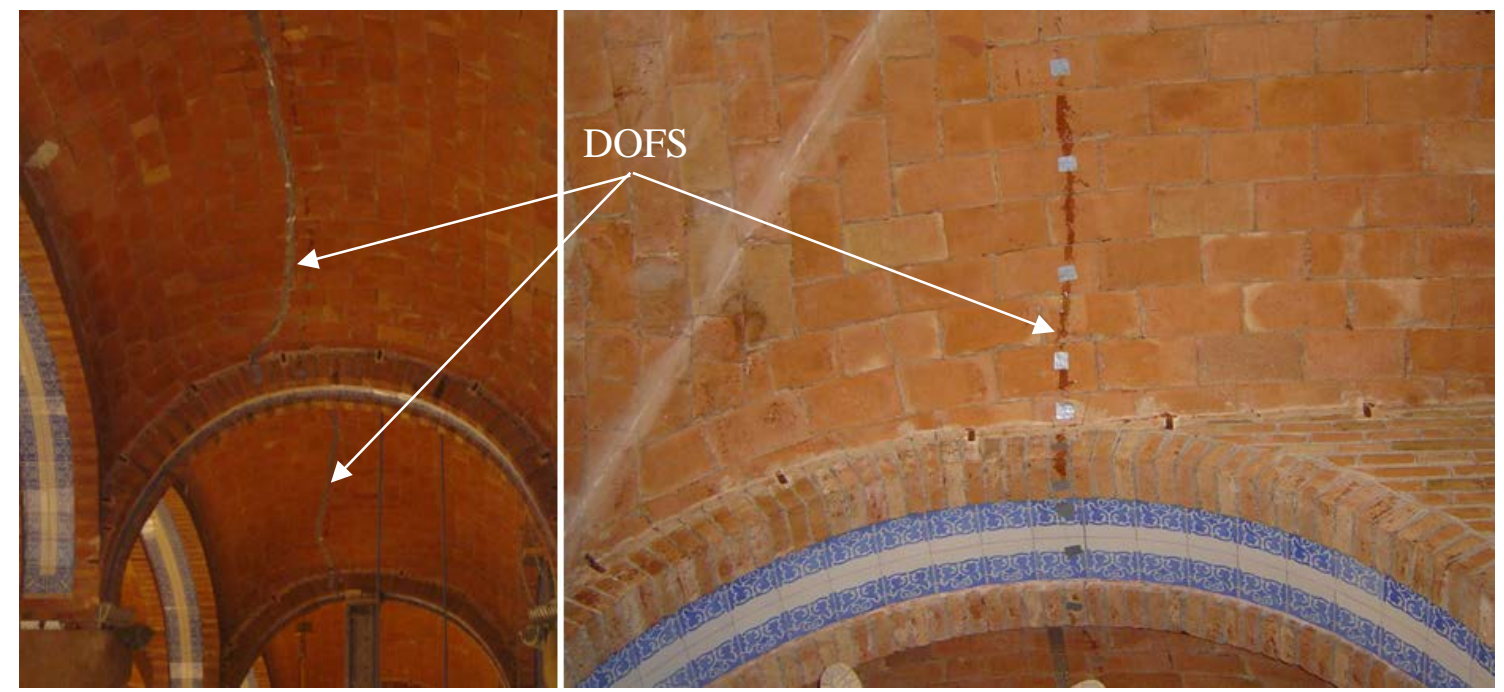

Figure 11. DOFS installed on the masonry vaults

The continuous monitoring in space of the whole affected area because of the column removal could be hardly achievable by using conventional sensors that are normally used for discrete monitoring (strain gauges, LVDT). Thus, in order to analyse and monitor the correct stress distribution of the slab supported by the columns during the replacement process in a cost-effective and in a truly distributed way, a DOFS was deployed. Otherwise, a large and unaffordable number of sensors would be required. The DOFS monitoring system was placed in a strategically zone sensible to the evolution of movements and crack forming and widening, as seen on Figure 6 and Figure 11.

In this application, a single $50 \mathrm{~m}$ long sensor was deployed enabling the performance of the SWI technique with 5000 points being interrogated and the signal from the sensor recorded simultaneously with a spatial resolution of $1 \mathrm{~cm}$. Nevertheless, for practicality reasons not the entire length of the fiber is adhered to the structure (see Figure 6) and only around $38 \mathrm{~m}$ of fiber was bonded to the structure. 


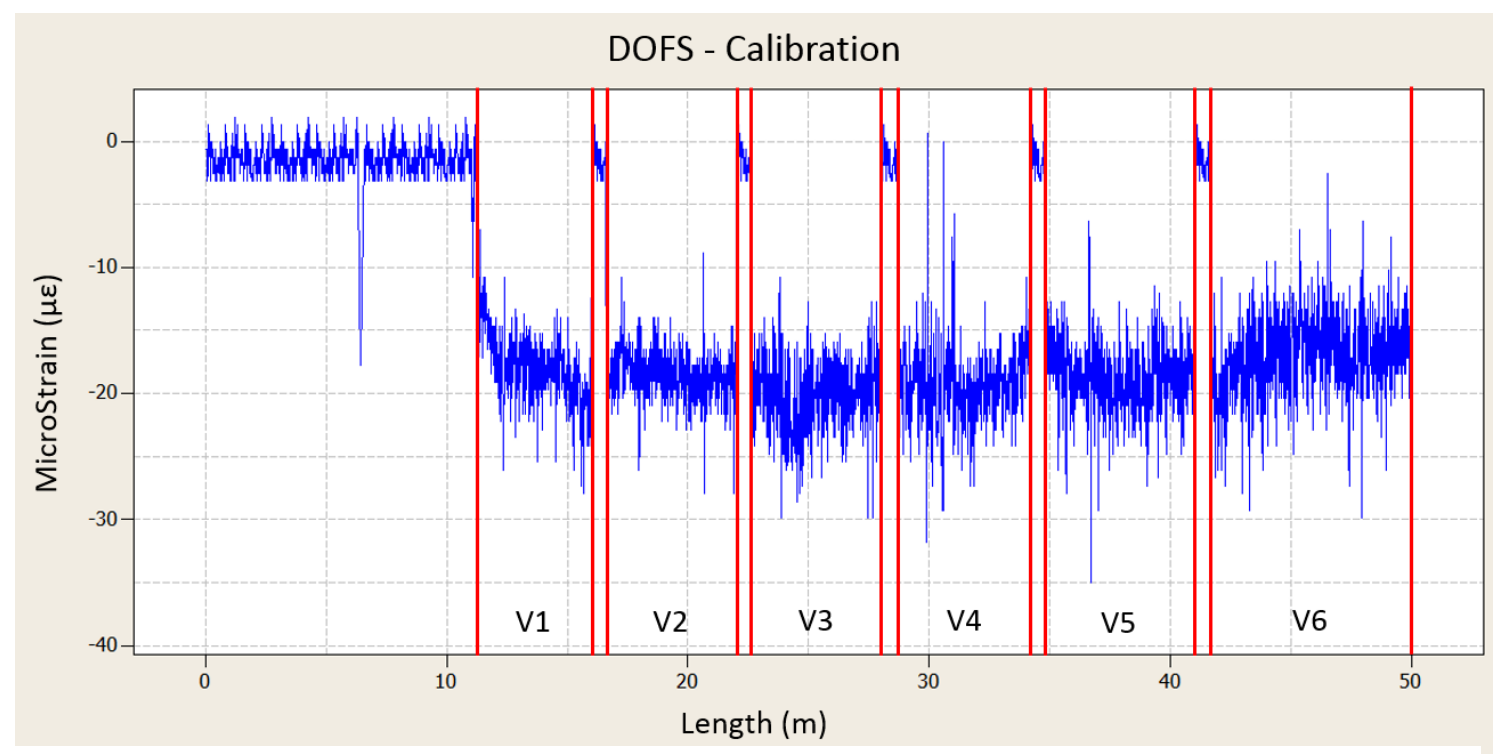

Figure 12. DOFS initial calibration

Previously to the start of the DOFS measuring under construction works, it was necessary to obtain an initial calibration of the system as shown in Figure 12. This provided the zero point from where the strains were measured. From the results presented in Figure 12, two clearly bands are highlighted. A first one where the strain is practically null (microstrain in the order of $0-5 \mu \varepsilon$ ) and a second one, where nonzero values with an average of $20 \mu \varepsilon$ are obtained. The first $12 \mathrm{~m}$ of the fiber (necessary length required to reach the first monitored arch) corresponds to one of the areas where the fiber is not attached to masonry structure. Then, in the corresponding sections around 16, 22, 28, 34 and 41 meters, also a null strain value is recorded in a zone of around $60 \mathrm{~cm}$. This corresponds to the transition zone between low arches vaults where the fiber is also not bonded (see Figure 11).

The information acquired by the DOFS corresponds to continuous readings obtained in combined time intervals of: 1 reading per minute, 1 reading per 10 minutes and 1 reading each hour. From this extensive data, the critical values (maximum and minimum) are analysed and used to generate the envelope response graphs. 


\subsubsection{Results}

The main objective of this deployed monitoring system was the detection and location of the premature appearance of cracks as well as their posterior evolution.

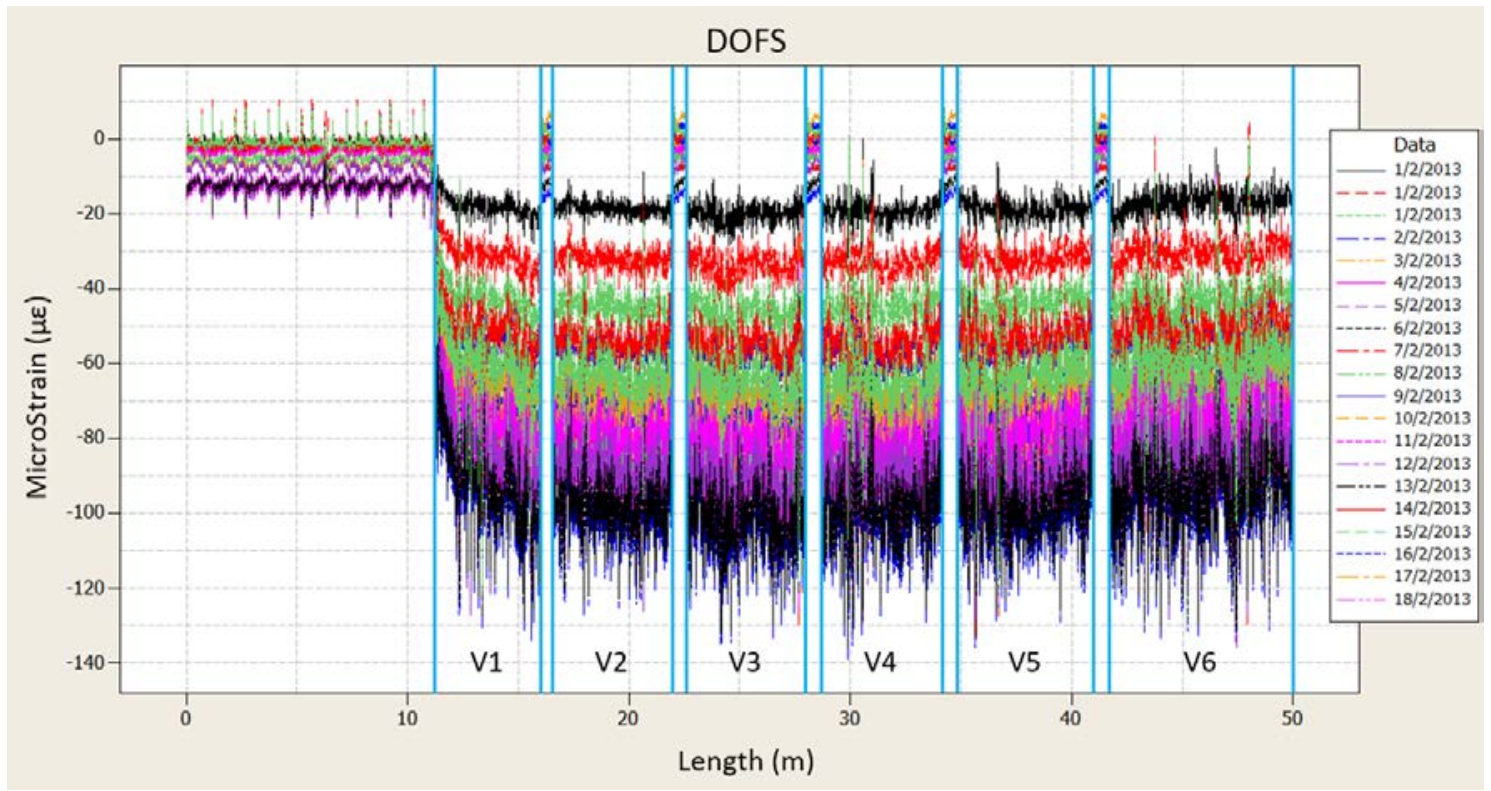

Figure 13. DOFS measurements for the whole length of the fiber during different days of the columns replacement

Figure 13 shows the superposition of measurement plots obtained in the days between the $1^{\text {st }}$ and $18^{\text {th }}$ of February of 2013. In this figure, the obtained strain along the entire length of the fiber is displayed. Here it is possible to observe the evolution of the measured strains in each of the instrumented masonry vaults for the total monitoring period. Due to the distributed capacity of this technology, it is possible to analyse separately this evolution for each vault as seen in Figure 14. Nevertheless, in order to enhance and clarify the evolution of strain with time and length, it is advisable to further zoom the window of analysis as seen in Figure 15 for a zoomed section of $10 \mathrm{~cm}$. Furthermore, measurements at each point versus time can be plotted to better follow the evolution of works as seen in Figure 16. 


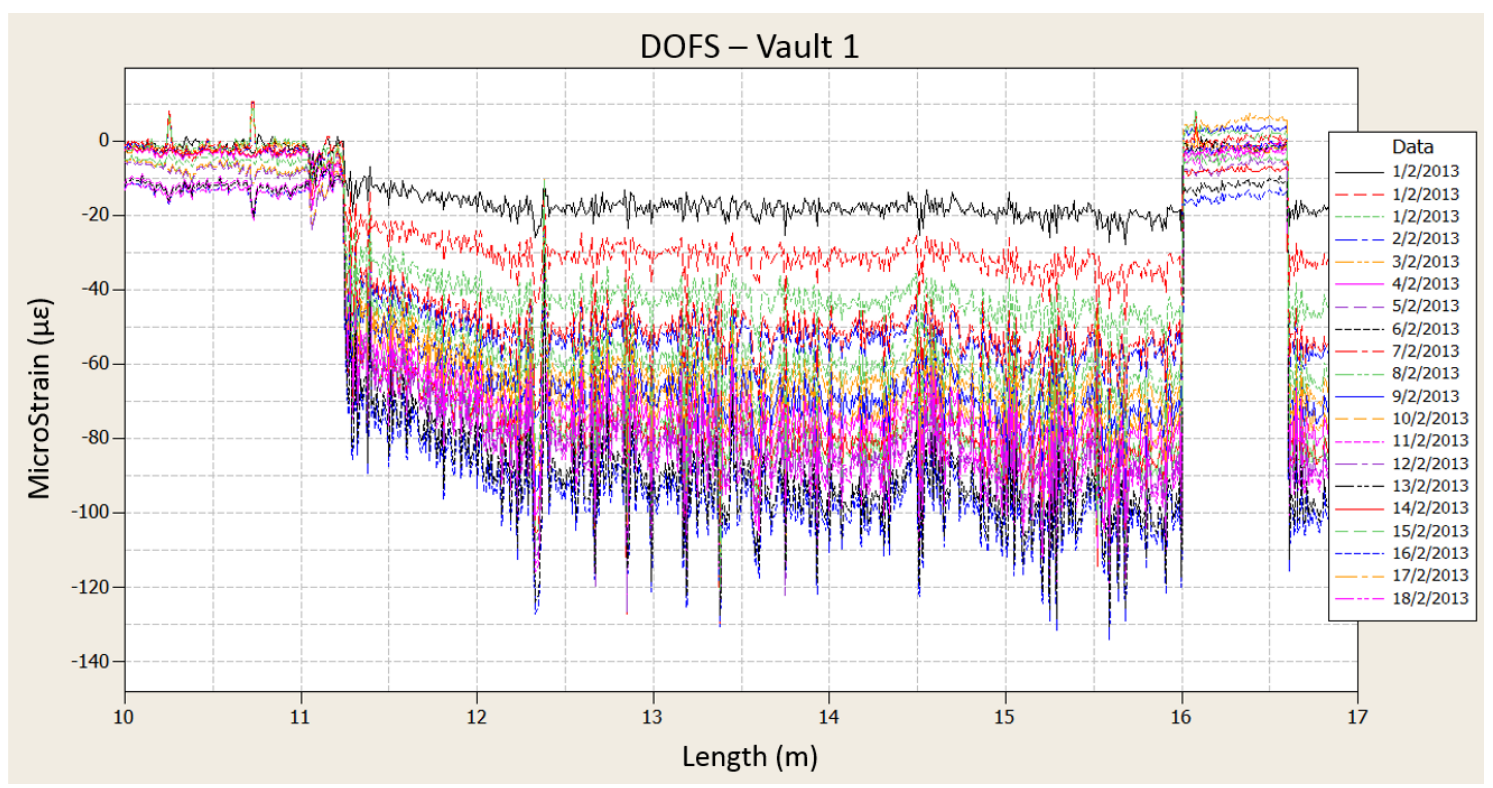

Figure 14. DOFS measured data for the instrumented vault V1

From this analysis, the range of deformation after the initial calibration was obtained. The range of strain change for the period that corresponds to the replacement of the first column ( $1^{\text {st }}$ of February of 2013) is of 20-40 $\mu \varepsilon$. After the replacement of the second column, an increase of the strain was observed with a maximum value of $100 \mu \varepsilon$. Since, it is necessary to subtract the initial calibration value of $20 \mu \varepsilon$ to this value, it is possible to conclude that the replacing operation caused an increment of the strain in the vault in the order of $80 \mu \varepsilon$, almost uniform along the whole roof. The objective of the operation was that during the removal of the old column and placement of the new one, the state of the strains in the vaults would not change significantly (thanks to the temporary steel frame) and also that any small change would be as uniform as possible in the whole roof. The observed increment in strain and its uniformity along the different vaults is in agreement to what was desired and predicted. 


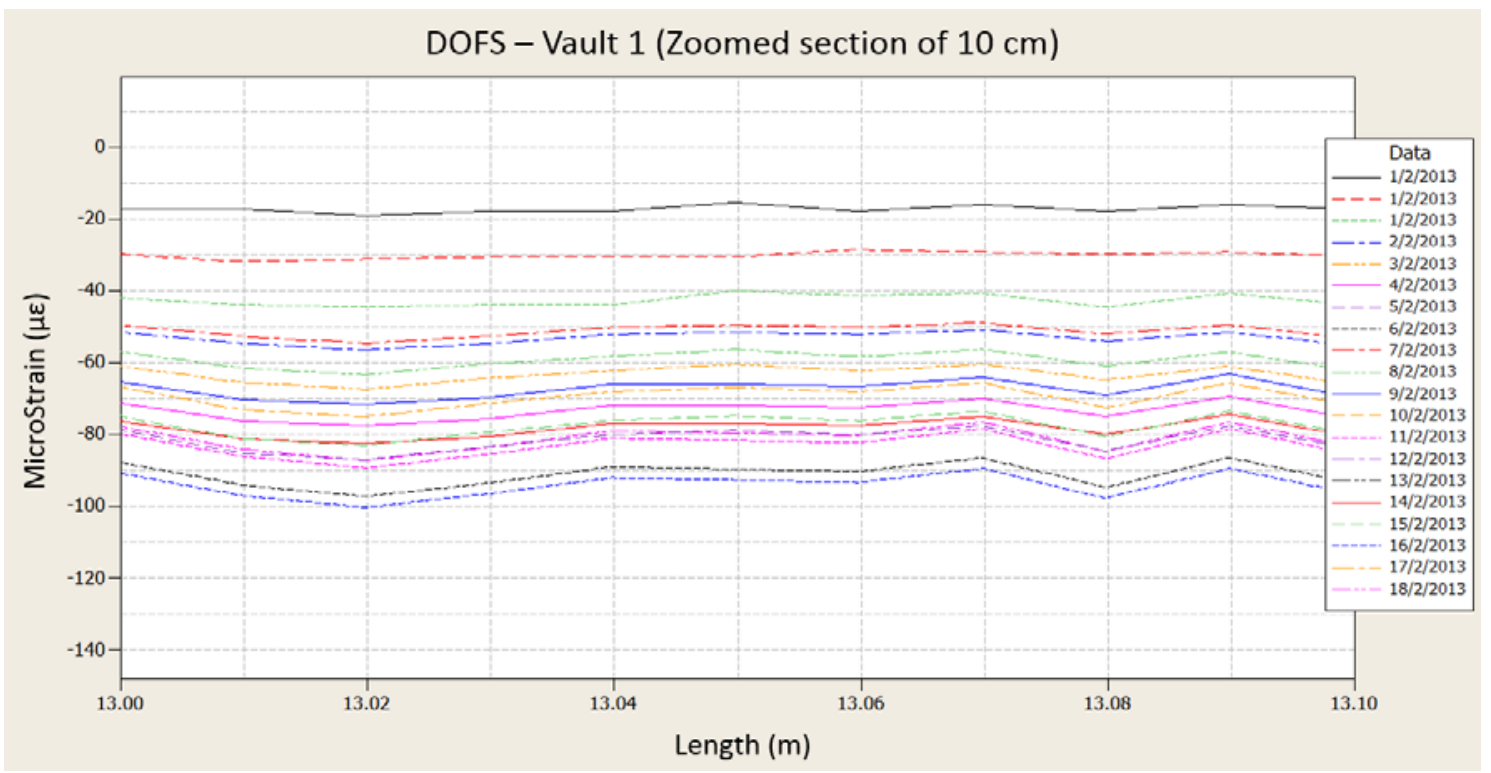

Figure 15. DOFS measurements for a $10 \mathrm{~cm}$ stretch of V1

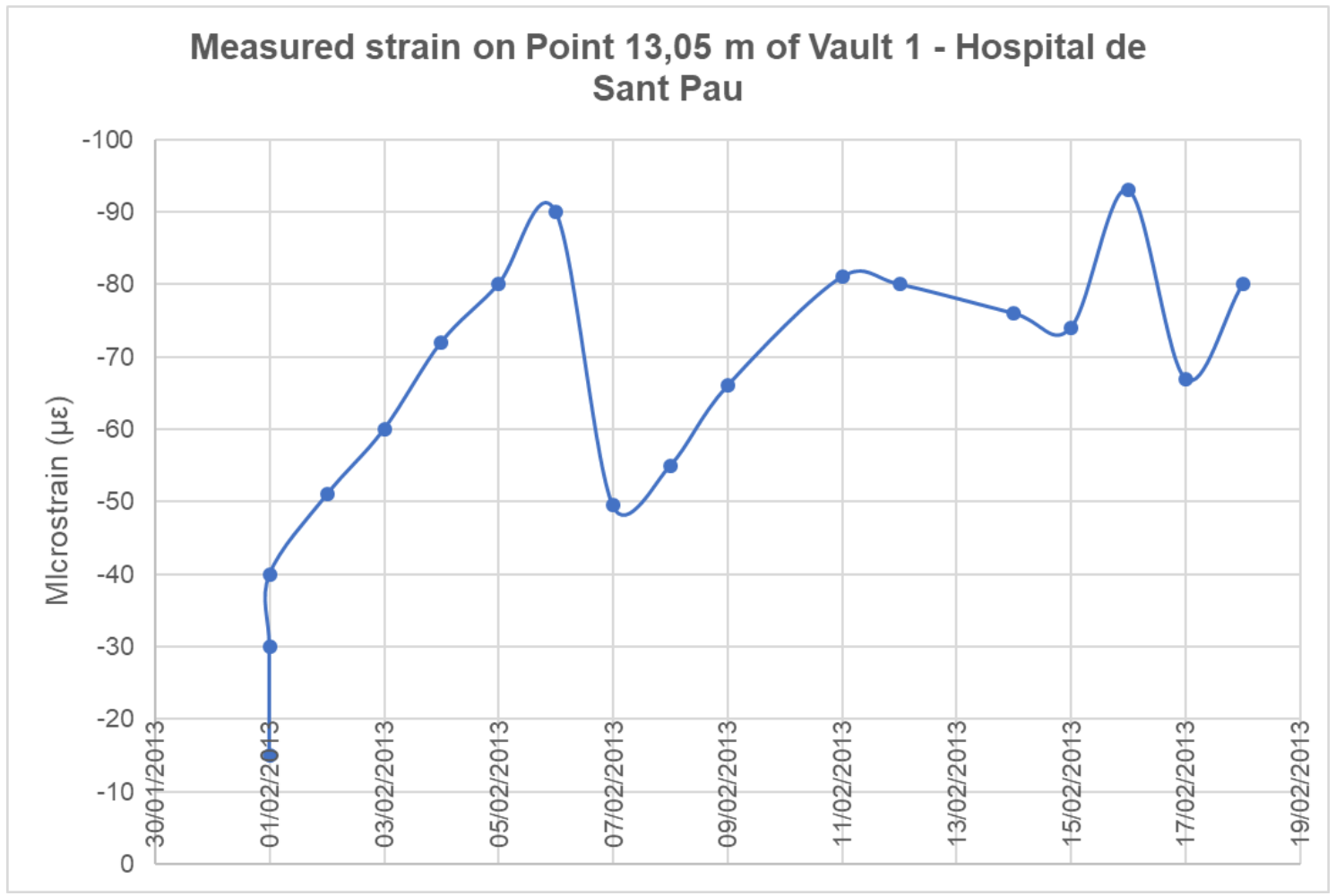

Figure 16. DOFS measurement for point $13.05 \mathrm{~m}$ of Vault 1

At every moment of the monitoring period, the structural response is under the service limit state since the strain increment generates minimal stresses to the material. According to the constitutive equations of the material, and specifically the stress-strain diagrams for the masonry, assuming an elastic and linear behaviour (acceptable for the 
obtained strain increment), the material has an increase of $0.14 \mathrm{MPa}$, for a characteristic compressive strength of $3 \mathrm{MPa}$ and a Young modulus in service of $1.8 \mathrm{GPa}$ as measured in the laboratory in samples cored from the removed pier.

Additionally, there was no evidence of the emergence of new cracks, either through visual inspection or from the obtained information acquired through the DOFS based monitoring system. As seen in Figure 13 and Figure 14, the observed peaks present small values without showing significant jumps in the measured strain, that would represent the formation of a crack at that location. By analysing the evolution of strain at one point over time, Figure 16, it is possible to observe the increase of compressive strains due to the implementation of the external metallic supports and the two drop-offs that correspond to the transfer of load between these and the columns replacement.

Finally, it is worth mentioning that in the last readings shown in Figure 15 and Figure $16\left(17^{\text {th }}\right.$ and $18^{\text {th }}$ of February), is observed a recovery in the strain of $20 \mu \varepsilon$, that perceives a certain turnaround and stabilization that was maintained throughout subsequent obtained readings. Therefore, it was concluded that the stresses in the masonry were stabilized without relevant modification in its structural response induced by the columns replacement. The replacement operation was carried out successfully and with the hospital in full operation as required by the owner.

In this application, due to the relatively controlled temperature environment and the fact that the monitoring period was only of a few days, it was not necessary to take into account the temperature effects in the strain data. This is not the case in the application described in the next section. 


\subsection{Sarajevo Bridge}

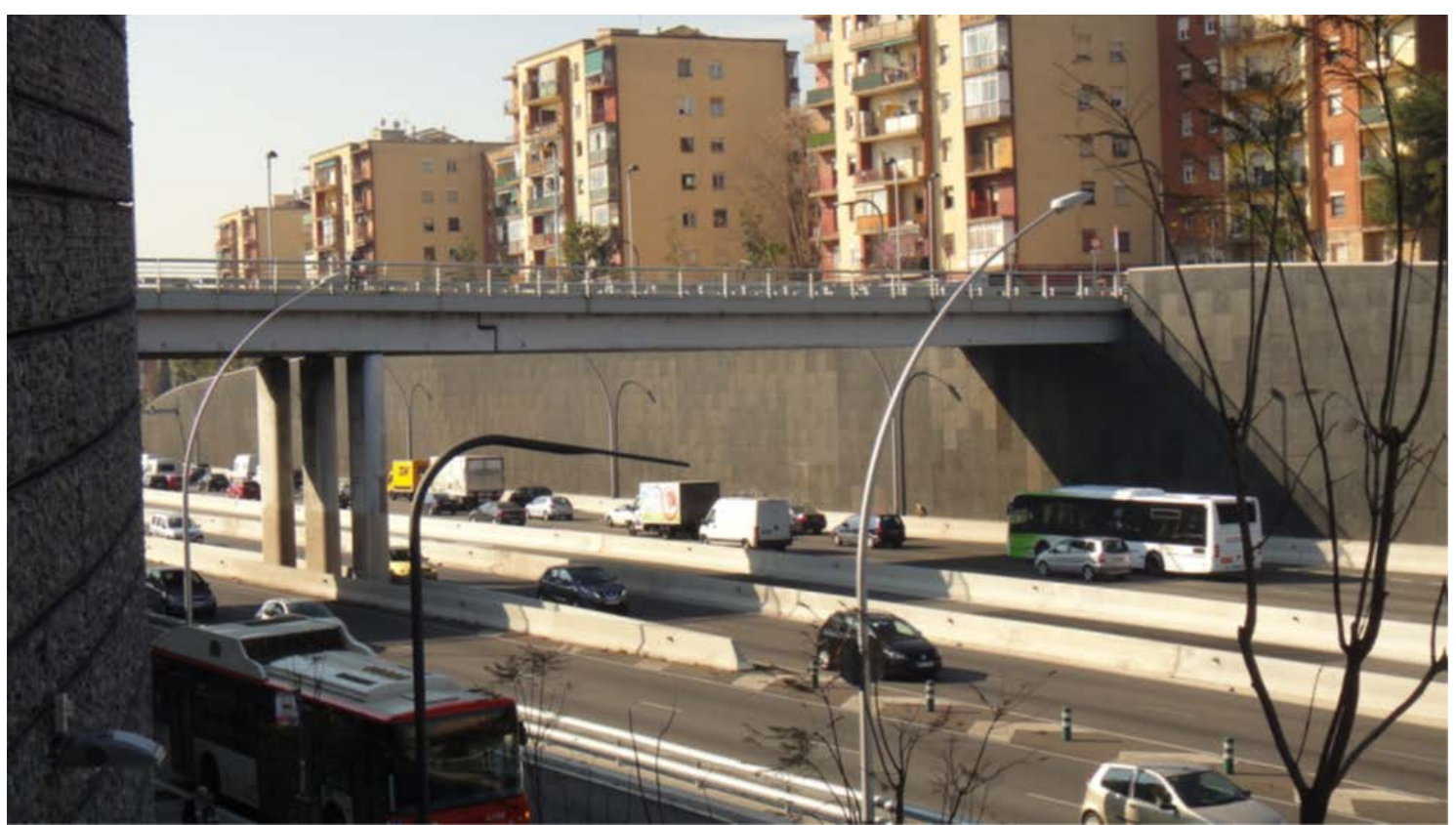

Figure 17. Sarajevo Bridge in Barcelona, Spain

This bridge is located at one of the main entrances of the city of Barcelona, Spain

(Figure 17). It is a simply-supported two span bridge with span-lengths of 36 and $50 \mathrm{~m}$

(Figure 18). Each span consists of three box-girder prestressed concrete beams connected by an upper reinforced concrete slab (Figure 19).

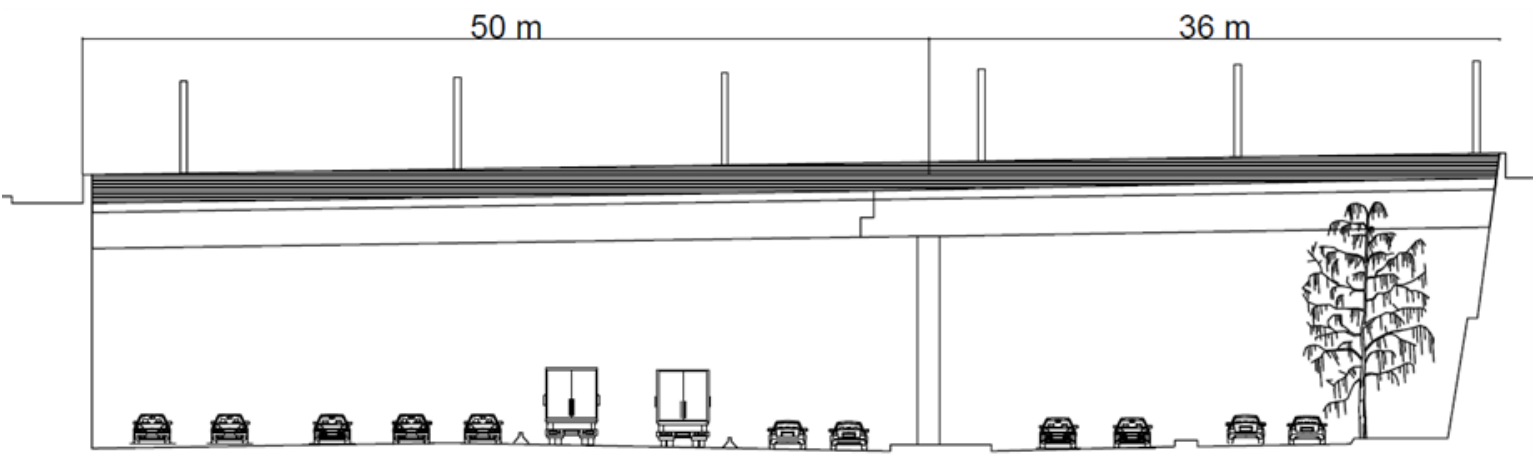

Figure 18. Side view of Sarajevo bridge 


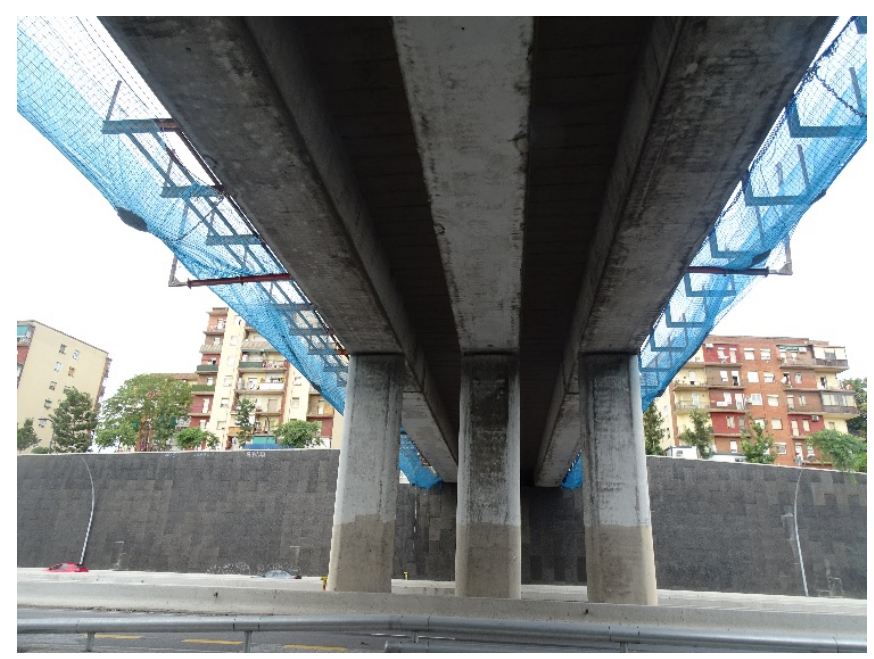

Figure 19. Bottom perspective of the bridge slab’s box-girders

In order to further increase pedestrian traffic and capacity as well as bridge aesthetics, it was decided to enlarge the deck. This procedure also involved the addition 
of overhead metal protections for the pedestrians. The construction works started on summer of 2015. Since the bridge is located at one of the main entrances of the city and due to its high traffic volume, closing the bridge to perform this deck widening was not an option. Also, it was not possible to close any of the existing traffic lanes underneath to place a temporary support due to the high volume of traffic entering the city in the 
rush hours. As a result of the change in the load pattern of the bridge, the absence of temporary support as well as the critical importance of the bridge in the Barcelona network, it was not wise to carry out the works without a close follow-up of the stresses induced in the material during the widening operation. In this way, it was decided to carry out the monitoring to detect major changes in the structural behaviour of the 
bridge and obtain information to assess the structural safety during and at the end of the construction work. DOFS were decided to monitor as much length of the bridge as possible. (Figure 20 and Figure 21). The sensors were placed in the areas more sensible to possible stress increments and cracking. For this reason, and since the beam on Barcelona's side was the part of the structure where a larger load increment was

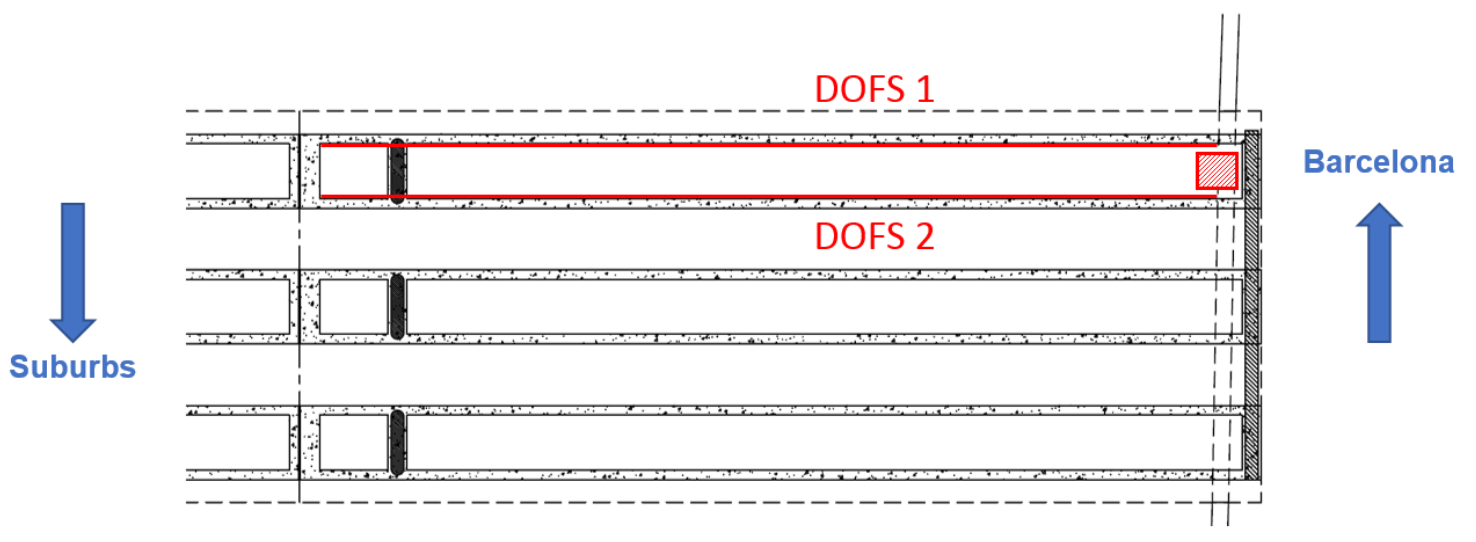

Bridge Cross Section

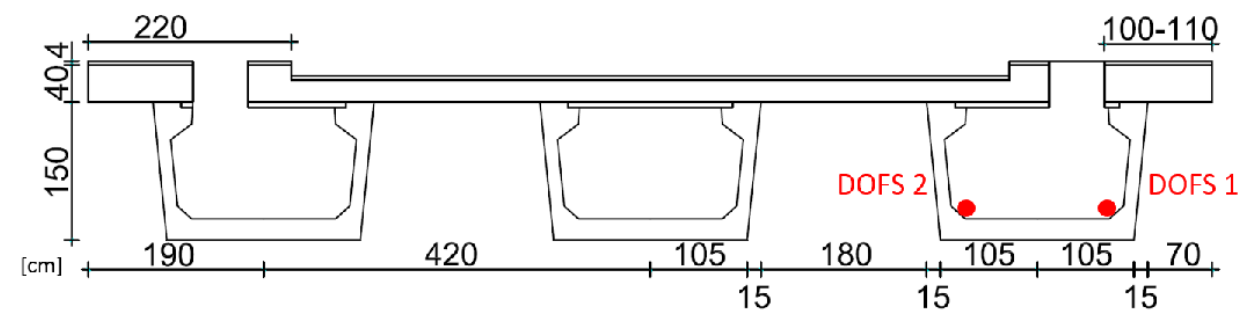

Work Station

Distributed Optical Fiber Sensor 
planned (due to an increase length of $2.30 \mathrm{~m}$ overhang), it was decided to instrument this beam (Figure 21).

As seen in Figure 20 and Figure 21, DOFS were placed inside the box girder
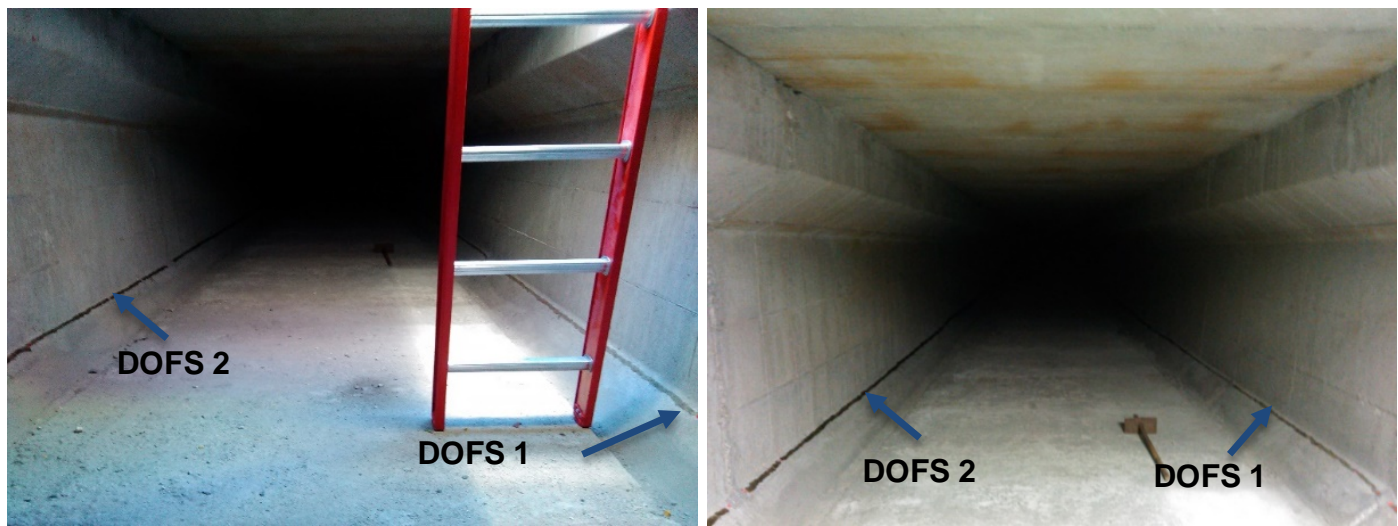

Figure 20. Deployed OBR system

allowing for a better protection of the sensors and an easier access for their installation and operation. The type of sensors as well as the installation procedure were similar to those described for the Hospital de Sant Pau. Due to the anticipated long duration of the monitoring period, the correct and careful implementation of these sensors assumes an even greater importance since any potential rupture or misuse of the fiber may compromise its performance. In this way, the use of two sensors instead of one also provides a desirable redundancy level.

\subsubsection{First Results}

The results obtained with both $50 \mathrm{~m}$ of optical fibers (36 $\mathrm{m}$ of which were bonded to the structure, adjusting to the span length) are analysed. Consequently, SWI was performed in a way that 3600 points were interrogated simultaneously with a spatial resolution of

Figure 21. General scheme of DOFS monitoring

$1 \mathrm{~cm}$. The information acquired by the DOFS corresponds to continuous readings 
obtained in 1 reading each 5 minutes. From this large amount of data, the critical values (maximum and minimum) are analysed and used to generate envelope response graphs.

Table 1. Summary of the monitoring events

\begin{tabular}{|c|c|}
\hline Date & Description \\
\hline 29/06/2015 & 2 hrs 30 min measurement - DOFS 1 only \\
\hline 16/07/2015 & 3 hrs 20 min measurement - DOFS 1 only \\
\hline 06/08/2015 & 7 hrs measurement - DOFS 2 only \\
\hline 15/09/2015 & 7 hrs measurement - DOFS 1 only \\
\hline 01/10/2015 & 5 hrs measurement - DOFS 2 only \\
\hline 02/10/2015 & 1 hrs 30 min measurement - DOFS 2 only* \\
\hline 09/10/2015 & 5 hrs 30 min measurement - DOFS 1 only \\
\hline 04/11/2015 & 4 hrs measurement - DOFS $1^{* *}$ and DOFS 2 \\
\hline 10/12/2015 & 6 hrs 30 min measurement - DOFS 2 only \\
\hline 22/12/2015 & 3 hrs measurement - DOFS 2 only \\
\hline 18/01/2016 & 5 hrs 40 min measurement - DOFS 2 only \\
\hline $19 / 01 / 2016$ & 2 hrs 30 min measurement - DOFS 2 only \\
\hline 20/01/2016 & 3 hrs measurement - DOFS 2 only \\
\hline $18 / 02 / 2016$ & 7 hrs 40 min measurement - DOFS 2 only \\
\hline
\end{tabular}


Different events corresponding to different days were monitored as seen in Table 1. The data collected between June 29 and November 4 of 2015 was made in an alternate way between DOFS 1 and DOFS 2. However, starting from December 10 until 
the last measurement only data from DOFS 2 was collected since the sensor DOFS 1 ceased to work properly. After this event, a visual inspection was conducted on the instrumented area of the beam and it was possible to conclude, that some works carried 
out inside the box girder could have broken DOFS 1. Notwithstanding, the rest of the procedures were followed by the data provided by DOFS 2 .
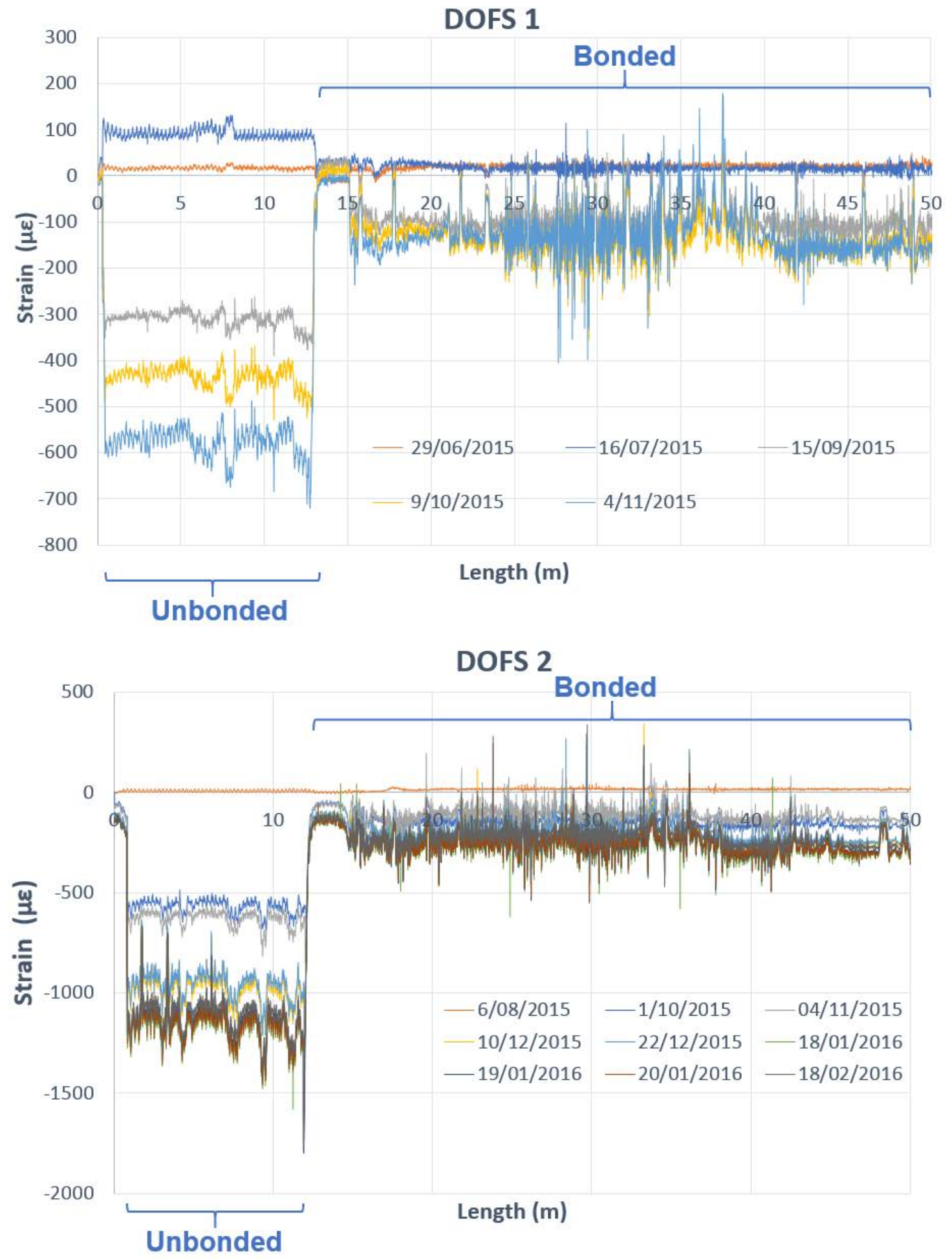

Figure 22. DOFS 1 and 2 readings evolution for the monitoring period interval 
In Figure 22, is plotted the evolution of the strains measured by the DOFS 1 and 2. It is important to point out, that this comparison is made with measurements from different days taking care of selecting readings within the similar time interval period in order to mitigate the influence of daily time dependent phenomenon. It is detected by both deployed fibers the increase of compression strain. This was a result of the construction works being done in this time window, such as the removing of asphalt layers (see Figure 23) and some bridge equipment in the first stages of the procedure and naturally the effect of the temperature variation from summer to winter.
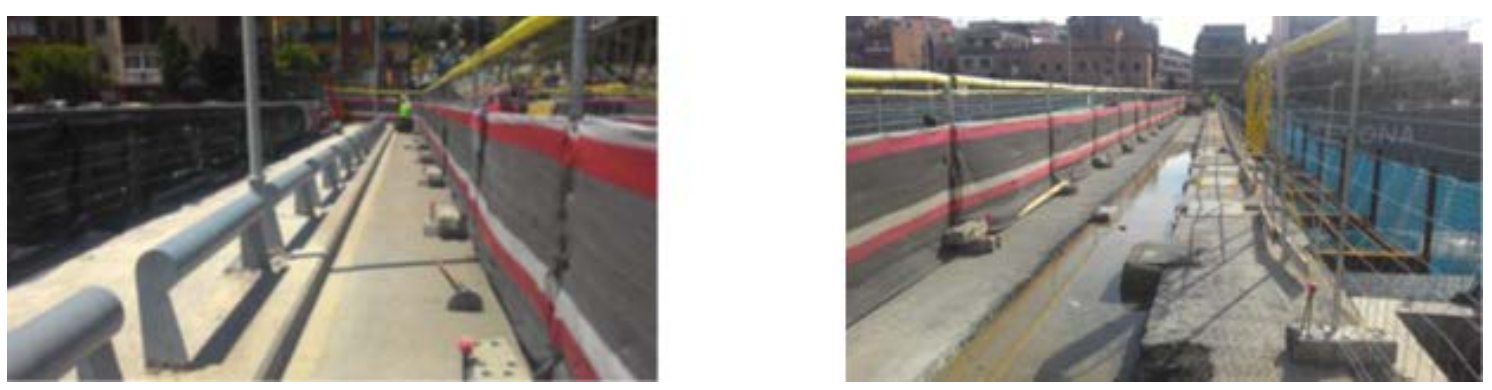

Figure 23. Bridge's load stage comparison between July (left) and September (right) of 2015

Furthermore, due to this relatively long monitoring period, the temperature variation not only affects the structure's behaviour but also the readings of the DOFS. Both the refractive index of the backscattered light and the materials which compose these sensors are dependent of these temperature changes, so a compensation of its effect on the monitoring output is required, as it is normally conducted in these type of applications, such as the case of discrete FBG sensors equipped with temperature sensors (Domaneschi et al, 2017).

In order to take into account these effects, in terms of spectral shift, the thermal output, $\Delta v_{T}$ can be expressed as: 


$$
\Delta v_{T}=\Delta v_{n}+\Delta v_{S}
$$

Where $\Delta v_{n}$ represents the refractive index-dependent spectral shift and $\Delta v_{S}$ is the coefficient of thermal expansion-dependent spectral shift.

There are two different ways to perform this thermal induced error compensation for measurements performed by OBR based DOFS where the thermal conditions are variable and where non-adhered segments of the DOFS are present (LUNA, 2014): point-to-point thermal compensation and thermal compensation by fiber loop.

\subsubsection{Point-to-point thermal compensation}

This thermal compensation method can be used in the situation where significant temperature gradients are expected throughout the entire active length of the DOFS. Here, an unbonded fiber segment is implemented beside the bonded fiber segment, floating in a tube. Therefore, the output of this unbonded segment is only dependent of the temperature variation and can be used to perform a point-to-point compensation of the mechanical strain measurements of the bonded fiber as represented in Figure 24.

In this way, Equation (2) can be formulated, where in order to obtain the mechanical strain in point $i$ of the bonded fiber segment, it is necessary to subtract the thermal effects outputs from the unbonded segment of the fiber in point $i$ to the total strain measured in point $i$ of the bonded segment.

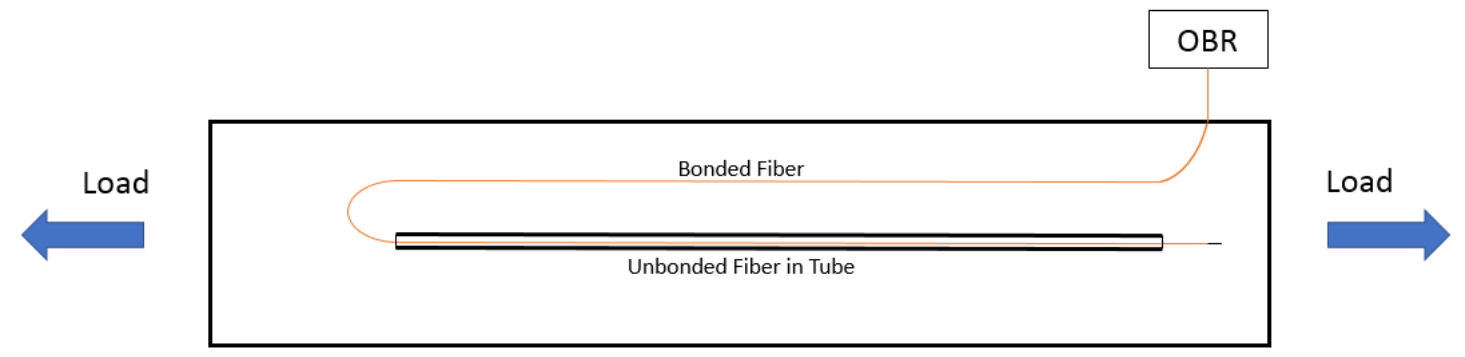

Figure 24. Point-to-point thermal compensation method scheme 


$$
\varepsilon_{L_{i}}=\left(\Delta v_{B_{i}} \times k_{\varepsilon}\right)-\left(\left(k_{n T} \times \Delta v_{U_{i}} \times k_{\varepsilon}\right)+\left(\Delta v_{U_{i}} \times k_{T} \times \alpha_{S}\right)\right)
$$

where,

$\Delta v_{B}=$ Spectral shift in bonded segment;

$\Delta v_{U}=$ Spectral shift in unbonded segment;

$k_{n T}=\frac{d n}{d T}$ effect - approximately 0.95;

$k_{\varepsilon}=$ Fiber strain conversion factor - approximately $-6.67 \mu \varepsilon / \mathrm{GHz}$

$k_{T}=$ Fiber temperature conversion factor - approximately $-0.801{ }^{\circ} \mathrm{C} / \mathrm{GHz}$

$\alpha_{S}=$ Substrate coefficient of thermal expansion $-10 \times 10^{-6}$ for concrete

\subsubsection{Thermal compensation by fiber loop}

For the situation where there are not significant local temperature gradients throughout the length of the optical fiber, this method can be used for compensation. In this case, a relatively short fiber loop can be created by leaving a small part of the sensor lying down on the monitored structural element without bonding it, as represented in Figure 25.

With this method, in order to obtain the pure mechanical strain generated during the monitoring period, it is necessary to subtract from the strain obtained in the bonded part of the fiber both the effects of the refractive index dependent apparent strain and the coefficient of thermal expansion dependent apparent strain. For the rest of this text the first is designated by RIAS (refractive index apparent strain) and the second by TEAS (thermal expansion apparent strain).

This compensation can be described mathematically by the same expression

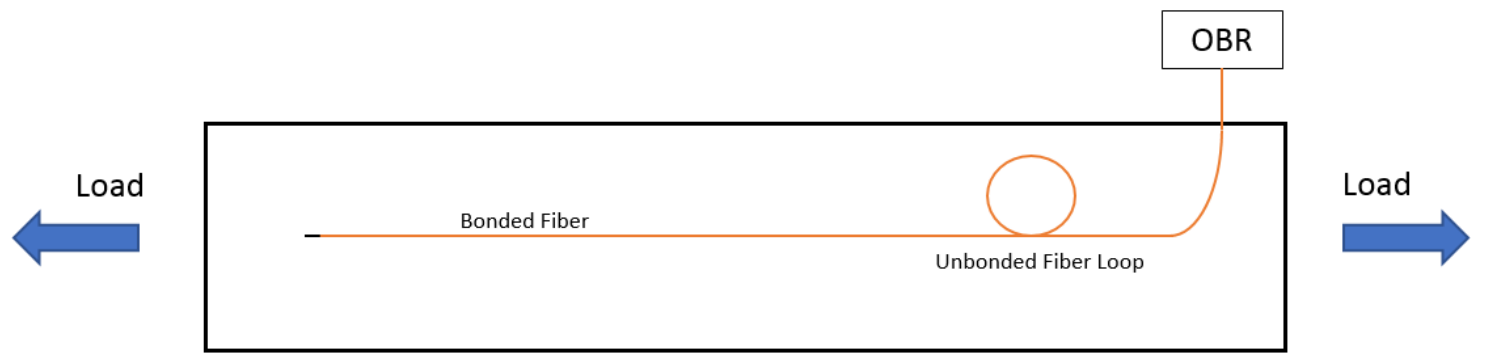

Figure 25. Fiber loop thermal compensation method scheme 
described before (2), with the only difference being that while in point to point thermal compensation, the spectral shift of the unbonded segment is subtracted in each measured point to the correspondent point of the bonded segment counterpart, in the

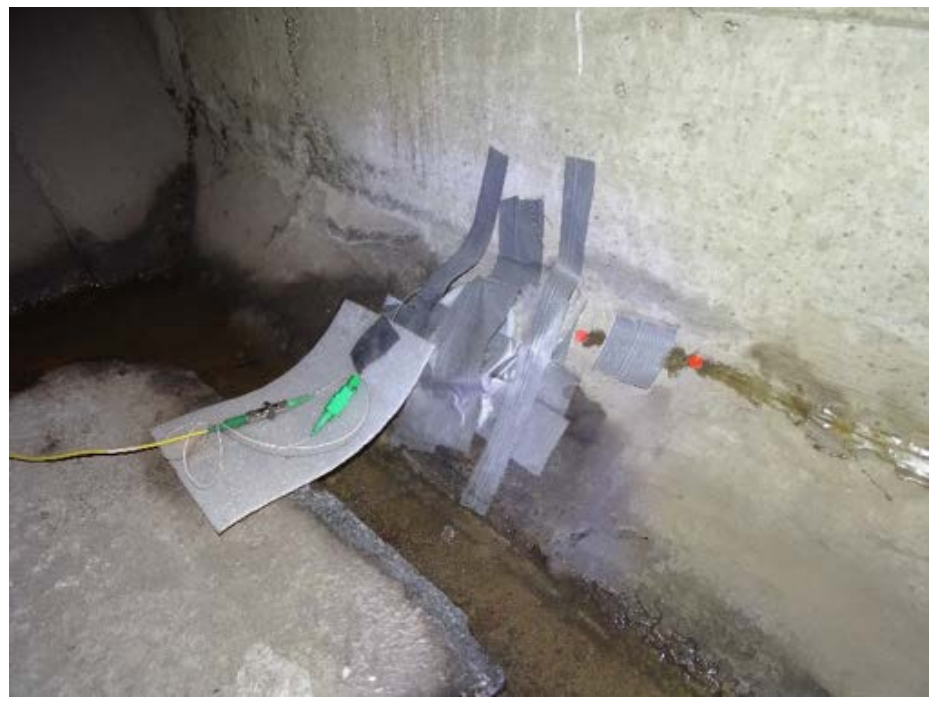

Figure 26. Unbonded loop of the DOFS

thermal compensation by fiber loop, an average of the spectral shift measured for the entire length of the unbonded segment is calculated and then subtracted to the calculated average of the measured data of the bonded segment. This was the method adopted in this real-world monitoring application, by the use of the unbonded loop segment of the fiber located at the end, inside the beam, as seen in Figure 26.

Since the strain measured by the first 14 meters of the fiber that are not bonded is exclusively dependent from the temperature variations, one may obtain from its measurements the information to calculate RIAS and TEAS. The values obtained in this temperature compensation process are presented in Table 2 and 3 . The results of Figure 22 were updated to the ones shown in Figure 27 and Figure 28.

Table 2. Temperature compensation for DOFS 1 


\begin{tabular}{|c|c|c|c|c|}
\hline Date & $\mu \varepsilon$ (mean) bonded fiber & RIAS $\mu \varepsilon$ (mean) & TEAS $\mu \varepsilon$ (mean) & Mechanical $\boldsymbol{\mu \varepsilon}($ mean) \\
\hline $\mathbf{2 9} / 06 / 2015$ & 11 & -1 & 1 & $\mathbf{1 1}$ \\
\hline $\mathbf{1 6 / 0 7 / 2 0 1 5}$ & 16 & 90 & -114 & $\mathbf{4 0}$ \\
\hline $\mathbf{1 5 / 0 9 / 2 0 1 5}$ & -89 & -321 & 405 & $\mathbf{- 1 7 3}$ \\
\hline $\mathbf{0 9 / 1 0 / 2 0 1 5}$ & -136 & -444 & 561 & $\mathbf{- 2 5 3}$ \\
\hline $\mathbf{0 4 / 1 1 / 2 0 1 5}$ & -153 & -574 & 726 & $\mathbf{- 3 0 4}$ \\
\hline
\end{tabular}

Table 3. Temperature compensation for DOFS 2

\begin{tabular}{|c|c|c|c|c|}
\hline \multicolumn{5}{|c|}{ DOFS 2} \\
\hline Date & $\mu \varepsilon$ (mean) bonded fiber & RIAS $\mu \varepsilon$ (mean) & TEAS $\mu \varepsilon$ (mean) & Mechanical $\mu \varepsilon$ (mean) \\
\hline $06 / 08 / 2015$ & 0.23 & -6.00 & 7.58 & -1.35 \\
\hline 01/10/2015 & -152 & -568 & 718 & -302 \\
\hline 04/11/2015 & -117 & -630 & 796 & -283 \\
\hline 10/12/2015 & -209 & -976 & 1234 & -467 \\
\hline 20/12/2015 & -202 & -953 & 1205 & -454 \\
\hline 18/01/2016 & -270 & -1112 & 1406 & -563 \\
\hline 19/01/2016 & -252 & -1143 & 1445 & -554 \\
\hline 20/01/2016 & -253 & -1160 & 1466 & -559 \\
\hline $18 / 02 / 2016$ & -219 & -1070 & 1356 & -502 \\
\hline
\end{tabular}

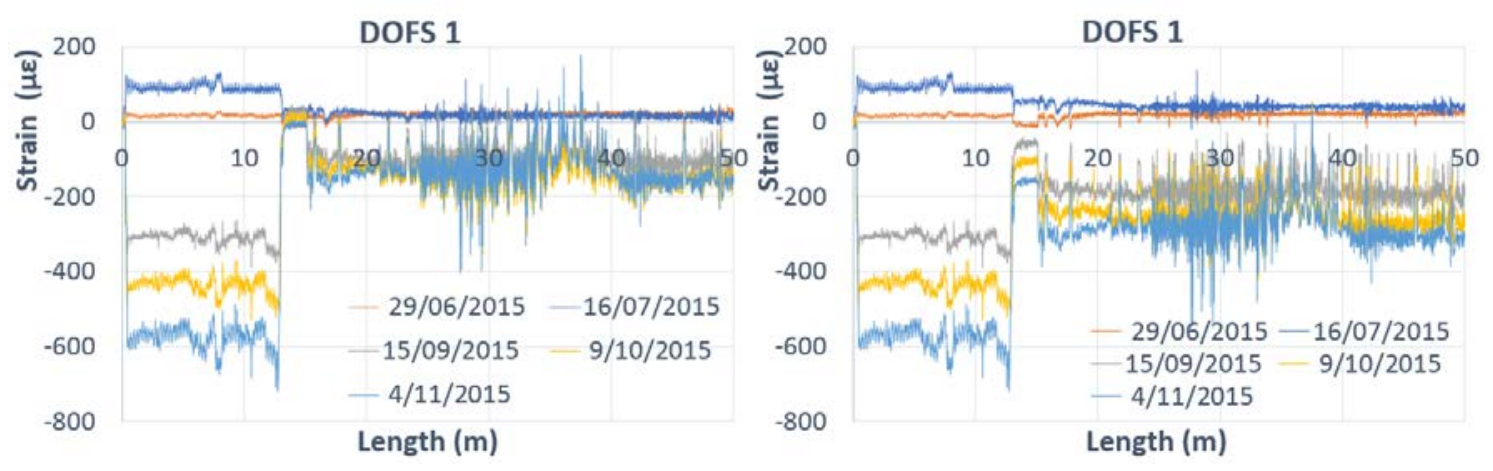

Figure 27. Comparison of DOFS 1 readings before (left) and after temperature compensation (right) 

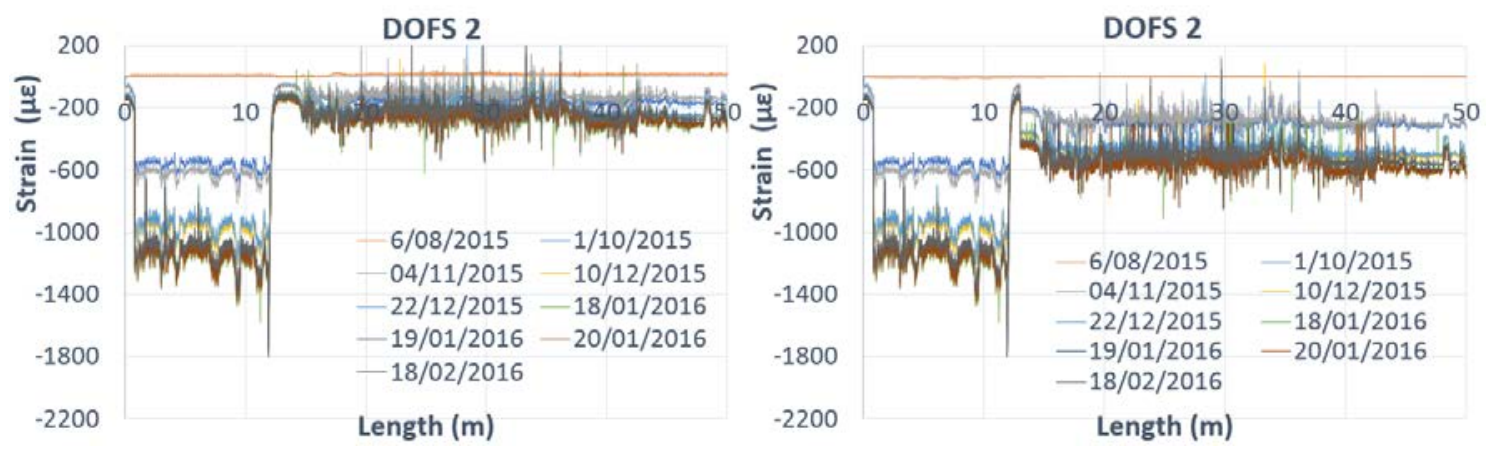

Figure 28. Comparison of DOFS 2 readings before (left) and after temperature compensation (right)

From these results, the effect of the general unloading that the bridge suffered due to the removal of the slabs, pavement and the milling of the agglomerate, when compared to the loading values at the time of calibration and the structure's shrinkage behaviour induced by the decrease of temperature, is further evidenced. Furthermore, this continuous increase of compression of the bottom part of the monitored span is also explained by a higher induced load on the adjacent span compared to the one applied to the instrumented span, as seen in the photograph taken in January observed in Figure 29. 


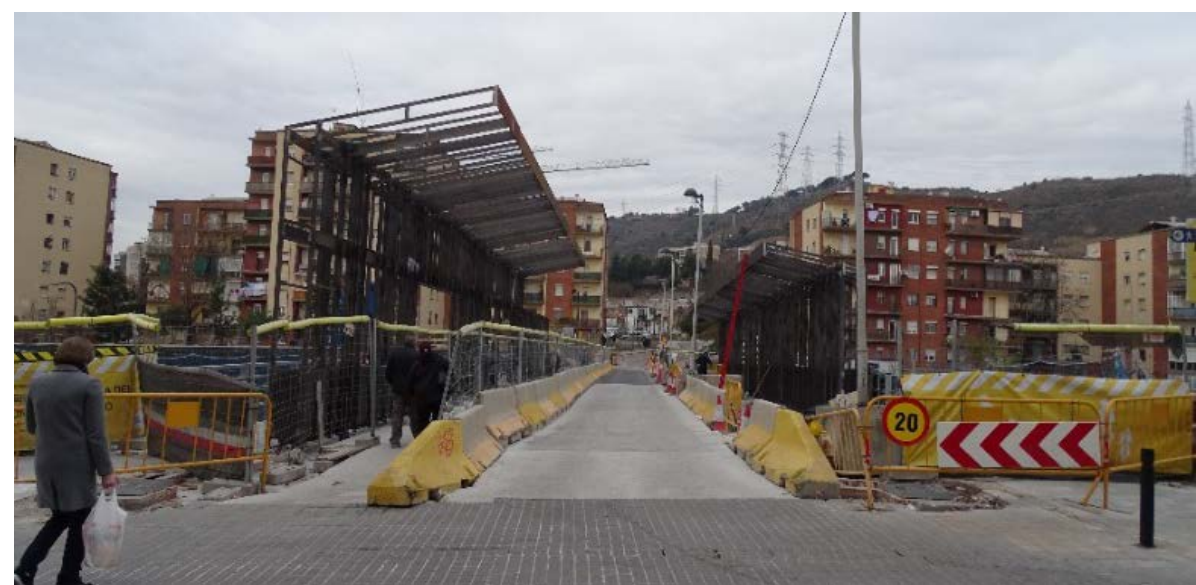

Figure 29. Photograph of the load increase on the non-instrumented span of the bridge taken in January 2016

Regarding the stresses analysis, and from the longitudinal deformation modulus of concrete $E_{c}$, it is possible to observe and conclude that, despite the variation of strain, excessive stresses are not induced to the concrete during the construction works.

In this way, from DOFS 1 the biggest strain variation was observed for $-304 \mu \varepsilon$ which corresponds to a stress change of $11.42 \mathrm{MPa}$. Regarding the measurements of DOFS 2, the biggest variation was detected in January for $-563 \mu \varepsilon$ that is equivalent to a stress increase of $21.16 \mathrm{MPa}$. Consequently, it is possible to conclude that these observed stress increments did not induce significant changes in the bridge structural behaviour since they are permissible and acceptable for this type of bridge, enhanced by the fact that these variations are of compressive nature.

The peaks and discontinuities in the data measured by the DOFS are representative of the joints between the prefabricated beams where the distributed optical fiber suffers from lack of bonding and other locations where due to the roughness or small cavities present near the surface, as a result of the heterogeneity of the concrete itself, the full and proper bonding between the sensor and the structural surface was not completely achieved, as seen in Figure 30. To not be confused with the emergence of new cracks, the peaks, although presenting variations in their magnitude, 
remain stable in terms of their location. These variations of magnitude in their turn are a consequence of possible vibrations which are transmitted from the operational loads.

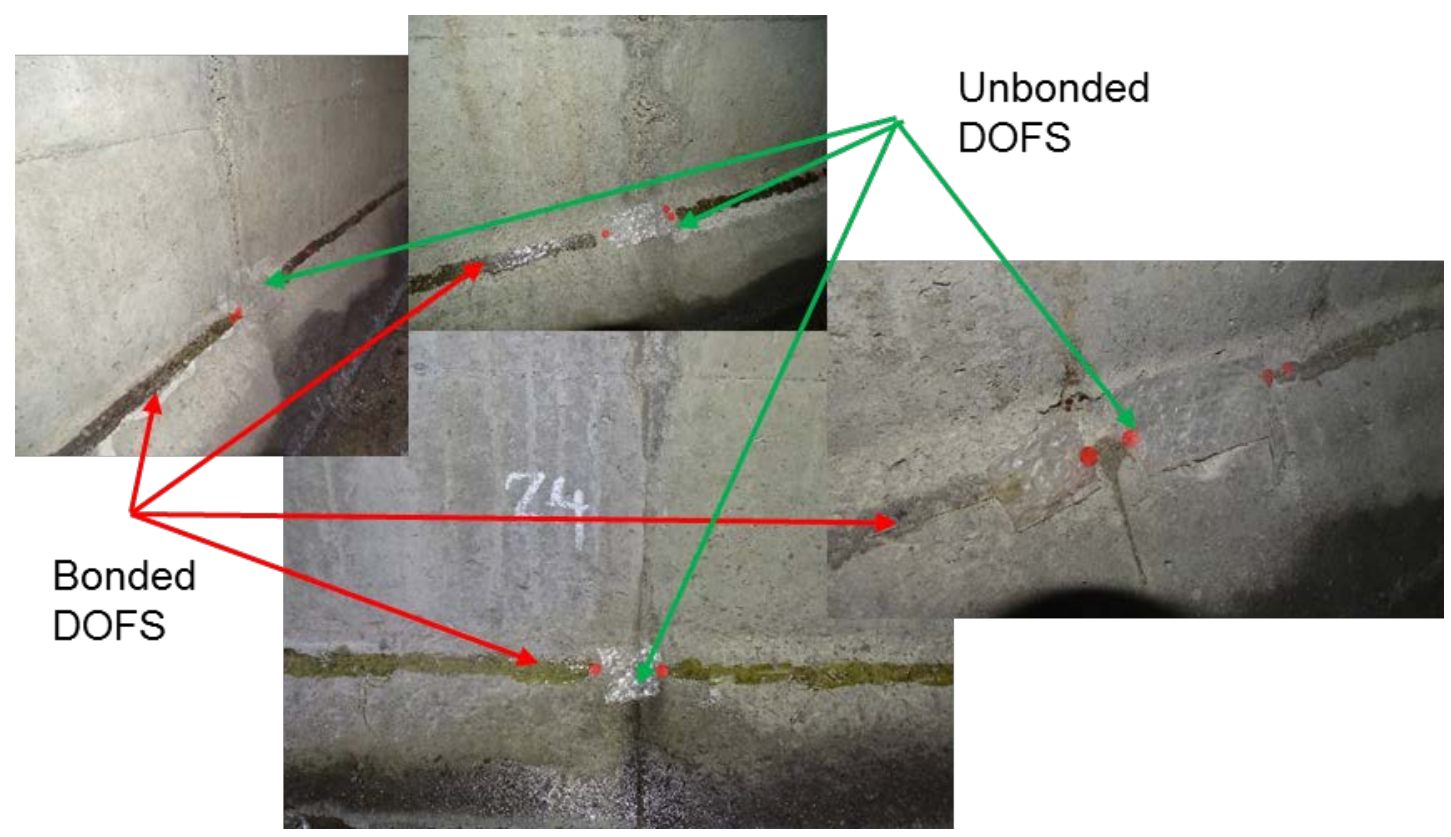

Figure 30. Some examples of unbonded points of the DOFS in the Sarajevo bridge application

The fact that the temperature compensation was made using the average of the entire length of the deployed fiber limits the obtained measurements to a more global structural behaviour analysis, where it is assumed that the ambient temperature is the same all along the box-girder. This could be corrected by the use of the other mentioned thermal compensation method (point-to-point measurement compensation) or the use of two or more thermometers in different locations of the DOFS to have a measure of the ambient temperature along the deployed fiber.

Notwithstanding, with the results obtained from the method adopted in this application it is possible to improve the results. This is achieved by dividing the entire length of the DOFS in different segments. In this way, it is proposed to divide the sensor in 5 different sections - S0, S1, S2, S3 and S4 - where a local temperature compensation is performed in the same way as explained before for the entire length of 
the sensor. For both deployed fibers the length of each segment is characterized as described in Table 4.

Table 4. Segment Length Definition for Extended Temperature Compensation

\begin{tabular}{|c|c|}
\hline Segment ID & Length (m) \\
\hline S0 & $0.5-12.7$ \\
\hline S1 & $13.3-15.0$ \\
\hline S3 & $15.0-24.0$ \\
\hline S4 & $24.0-37.5$ \\
\hline
\end{tabular}

The mechanical strain measured for each section is represented in Table 5 and

Table 6 for the different periods of observation

Table 5. Section localized temperature compensation for DOFS 1 (microstrain)

\begin{tabular}{|c|c|c|c|c|c|}
\hline Segment ID & $29 / 06 / 2015$ & $16 / 07 / 2015$ & $15 / 09 / 2015$ & $09 / 10 / 2015$ & $04 / 11 / 2015$ \\
\hline S0 & 10.4 & 113.5 & -389.3 & -546.3 & -670.7 \\
\hline S1 & -2.8 & 45.3 & -56.1 & -104.1 & -160.4 \\
\hline S2 & 13.4 & 23.0 & -168.3 & -230.8 & -281.8 \\
\hline S3 & 17.0 & 27.8 & -172.1 & -246.5 & -267.2 \\
\hline S4 & 18.2 & 29.9 & -172.3 & -254.5 & -291.1 \\
\hline
\end{tabular}

Table 6. Section localized temperature compensation for DOFS 2 (microstrain)

\begin{tabular}{|c|c|c|c|c|c|c|c|c|c|}
$\begin{array}{c}\text { Segmen } \\
\text { t ID }\end{array}$ & $\mathbf{0 6} / \mathbf{0 8} / 2$ & $\mathbf{0 1 / 1 0 / 2}$ & $\mathbf{0 4 / 1 1 / 2}$ & $\mathbf{1 0 / 1 2 / 2}$ & $\mathbf{2 2 / 1 2 / 2}$ & $\mathbf{1 8 / 0 1 / 2}$ & $\mathbf{1 9 / 0 1 / 2}$ & $\mathbf{2 0 / 0 1 / 2}$ & $\mathbf{1 8 / 0 2 / 2}$ \\
\hline S0 & 14.1 & -707.7 & -771.0 & -1168.5 & -1177.5 & -1393.4 & -1383.2 & -1397.4 & -1353.6 \\
\hline S1 & 5.5 & -235.0 & -238.7 & -379.1 & -383.6 & -499.5 & -456.2 & -453.5 & -448.8 \\
\hline S2 & 17.1 & -286.0 & -271.2 & -443.8 & -446.2 & -539.0 & -536.5 & -534.8 & -504.8 \\
\hline S3 & 19.8 & -284.9 & -253.0 & -425.6 & -426.9 & -528.7 & -524.4 & -524.1 & -480.4 \\
\hline S4 & 20.7 & -311.1 & -287.0 & -477.4 & -479.3 & -565.2 & -571.7 & -571.6 & -532.3 \\
\hline
\end{tabular}

Due to the presence of the peaks, the strain is possibly masked and its real distribution along the instrumented box-girder is not clear. To observe a better strain 
distribution, a spatially averaging only of the mechanical strains for S1, S2, S3 and S4 segments was performed and plotted in and Figure 32. These are the values also present in Tables 5 and 6.

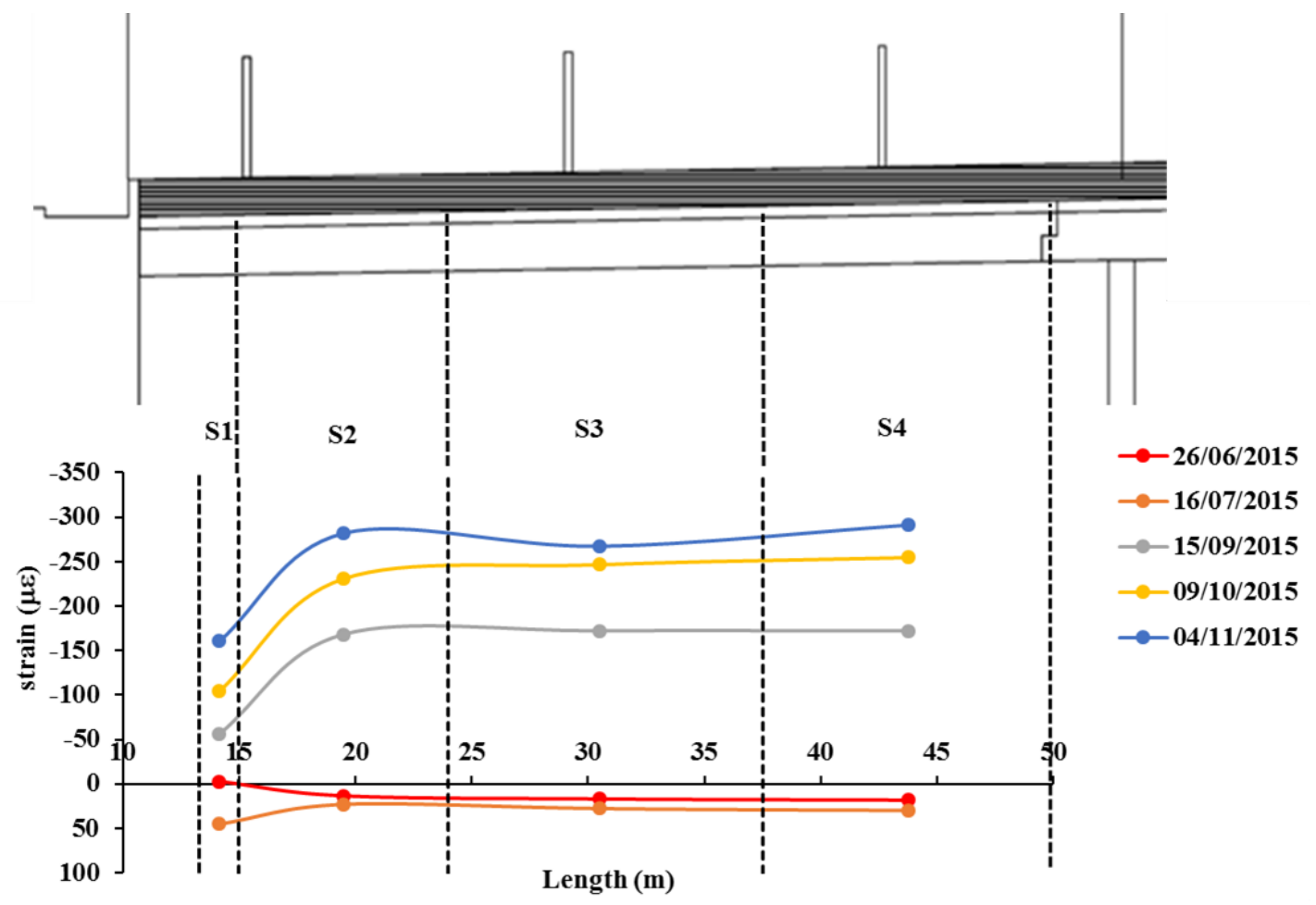

Figure 31. Mean mechanical distribution for DOFS1 


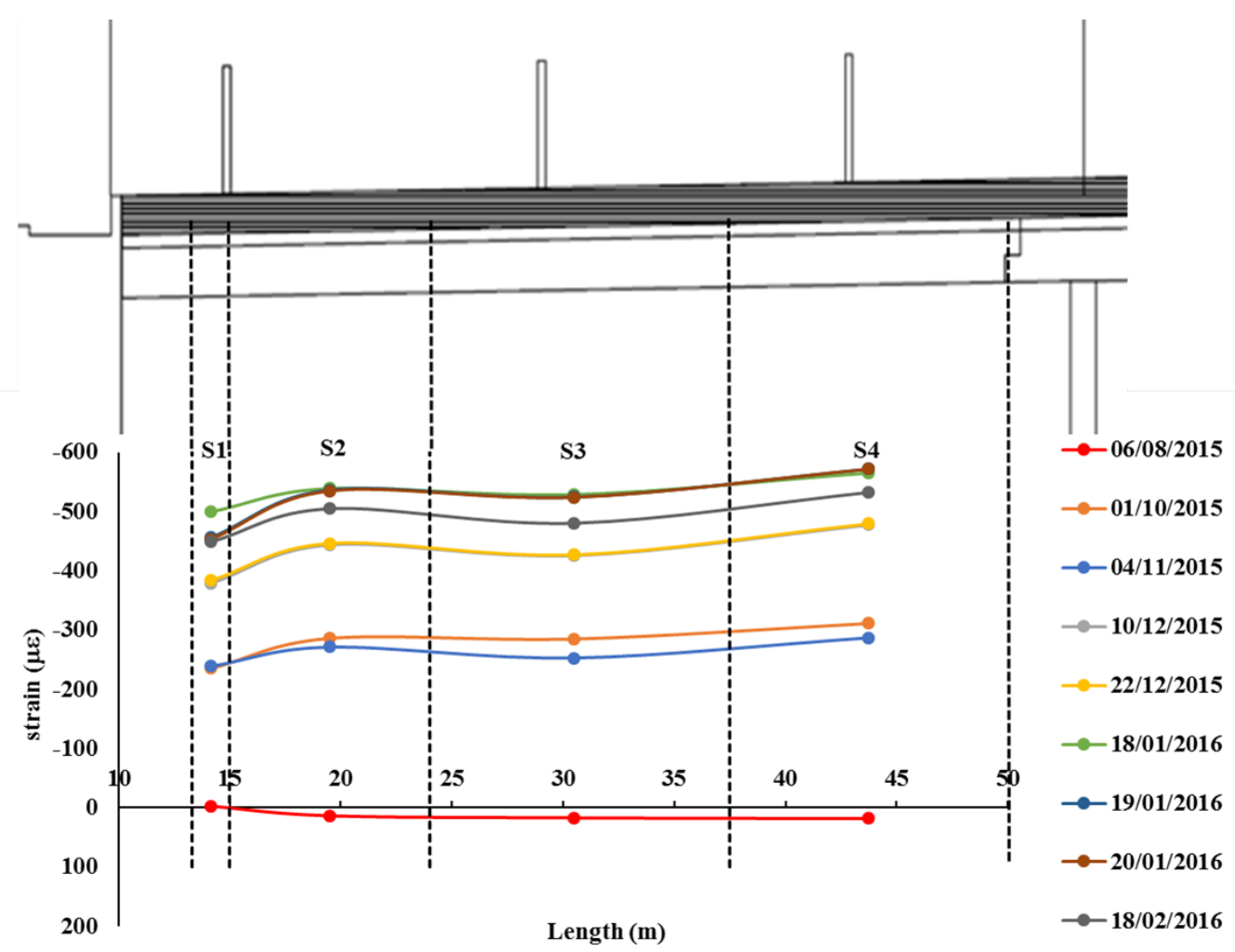

Figure 32. Mean mechanical distribution for DOFS2

In segment S1, mean mechanical strain values lower than those generally present in the rest of the DOFS length can be shown. This decrease is due to the influence of the support system (elastomeric bearings) on the bridge kinematics. The mean mechanical strain distribution is almost uniform in the rest of the box-girder. This means that the applied forces in the deck that could produce variations of strain along the bottom part of the bridge were very small at the time of measuring the sensors, being therefore the strain mainly due to the uniform shortage of the box-girder associated to the decrease of temperature from summer to winter. Note that the difference in strain between August and February in the order of 500 microstrain (Figure 32) is very much plausible for a bridge like this and the climate in Barcelona.

This is also perceived and validated by analysing Figure 33 which plots the evolution of the average strain at each section over time for both instrumented DOFS. 


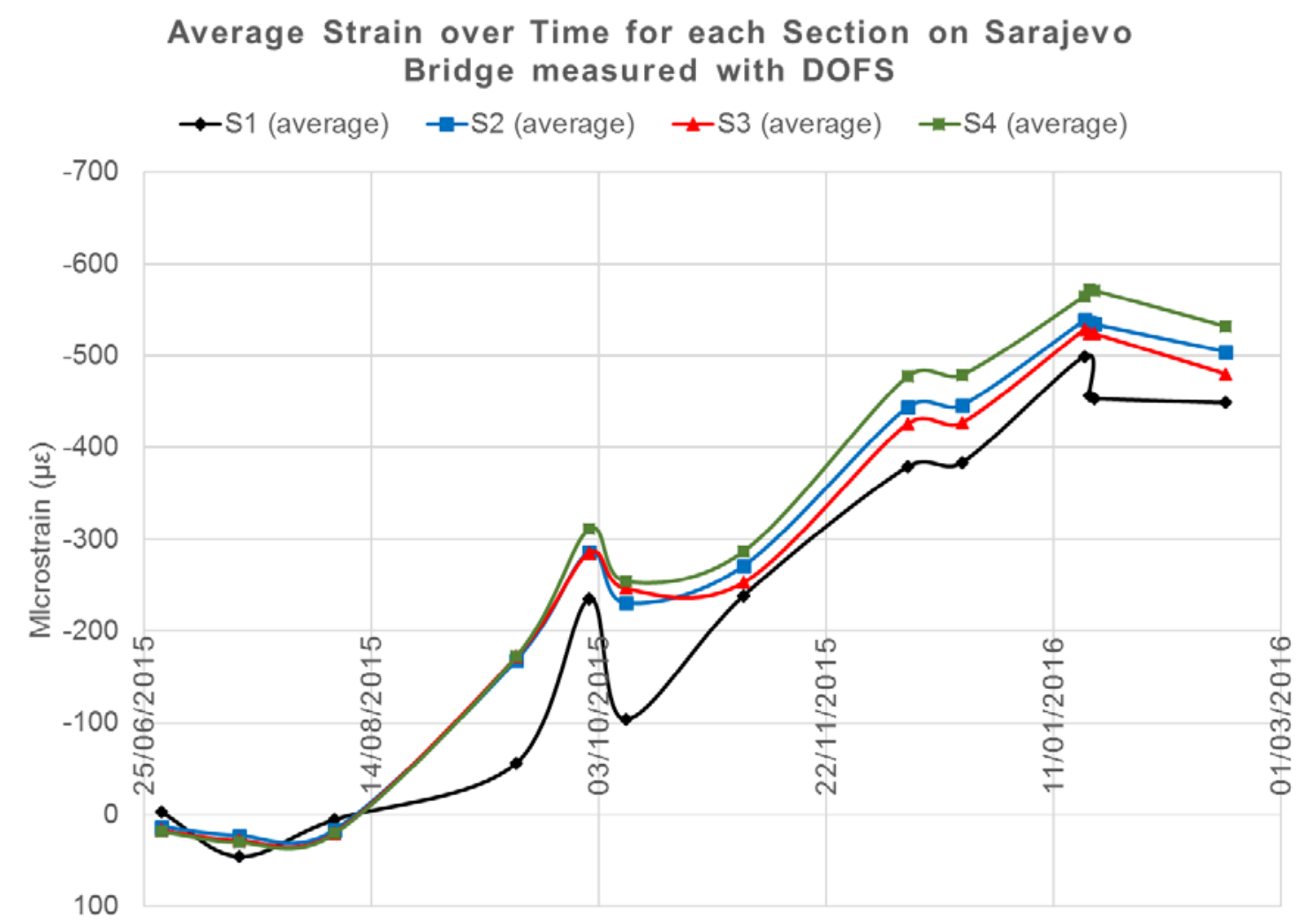

Figure 33. Evolution of average strain measured at each section over time

In Figure 33, as expected, the increase of compressive strains is observed from the summer to the winter period. It is also possible to observe some specific and short-term variations that correspond to the global effect of introduction and withdrawal of construction equipment to the deck and the variation of the applied load that is inherent to the deck widening procedure.

Some photos of the final stage of the structure after the completion of the aforementioned procedure can be seen in Figure 34. 

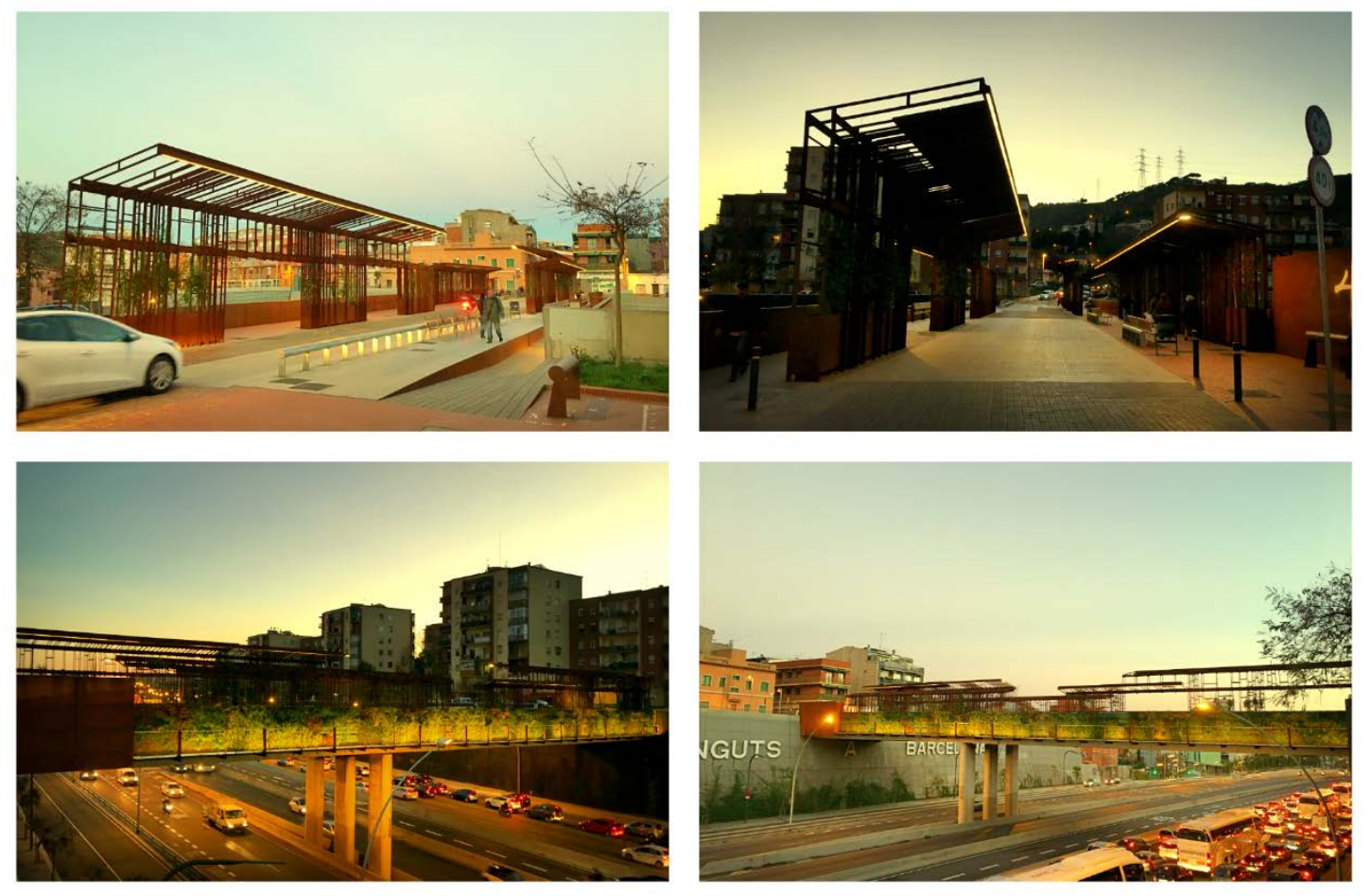

Figure 34. Sarajevo bridge after the completion of the rehabilitation works

\section{Conclusions}

In this paper, the successful application of distributed fiber optic sensors, DOFS, on the structural health monitoring of two real structures was presented. Due to their particularities, each one of these structures underwent changes in their structural behaviour without, nevertheless, ceasing to serve their purpose, i.e. accommodating patients in the case of the Sant Pau Hospital and the passage of vehicles and pedestrians in the case of Sarajevo bridge.

In this way, with the application of the DOFS technology it was possible to follow and monitor the structural behaviour in these structures during the different operations executed with the use of a relative small number of sensors and simple monitoring systems. With the DOFS readings at different dates, it was possible to easily detect the stresses increments in each structure and in this way, assess their actual safety. If anomalous changes were detected with the instrumentation, automatically the 
works would stop and necessary corrective measures would be taken. Furthermore, the evolution of strain variation along an extensive length of structure was achieved with a relatively simple and easy installation of only one sensor and one connection to a reading terminal.

Also, in this paper, two different types of applications were shown with two different types of structural materials (masonry and concrete), which showcases the versatility allowed by this technology and the feasibility to correctly bond the fiber to those materials.

Notwithstanding, there are still some improvements to be made regarding the application and use of the DOFS technology in real world scenarios. For example, it would have been interesting to obtain data from the two different fibers deployed on Sarajevo bridge in a quasi-simultaneous way in order to better evaluate the effects of transversal bending and torsion. This is a limitation imposed by the particular OBR system used in these applications.

Furthermore, the compromise between the protection coating of the sensors and their strain accuracy should be carefully assessed before its implementation in any real-world scenario structure. As seen in this document, when the location of the sensor might be accessed and handled during the monitoring period, the probability of its rupture is increased if not a considerable thick coating is used. However, in the situation where it is believed that the DOFS is located away from such events, the use of a thin coating is advised in order to allow for an increased accuracy.

In conclusion, this paper showcased the first application of OBR based DOFS technology in a masonry structure (at least that the authors are aware of), specially, with such an important historical value. Furthermore, it reports the first application of this technology for the monitoring of a real structure during a relatively extended period of 
time (in the case of Sarajevo bridge) where the topic of the thermal effects compensation on the sensor had to be addressed in a non-controlled environment. All of this serving as practical evidence for designers and rehabilitation engineers of the potential, advantages and disadvantages of the use of this sensing technology.

Nevertheless, with the results obtained in this work, the OBR theory associated with DOFS proved its reliability in SHM of civil engineering applications and continues to showcase the promising future of monitoring systems based on this technology.

\section{Acknowledgements}

This project has received funding from the European Union's Horizon 2020 research and innovation programme under the Marie Sklodowska-Curie grant agreement No. 642453.

The authors acknowledge the funds received from the Spanish Ministry of Economy and Competitiveness and the FEDER funds through the research grant BIA2013-47290-R and are also grateful to Vicente Alegre Heitzmann CEO of COTCA SA for his useful cooperation and by providing the ODiSI-A fiber Optic Sensing System. Furthermore, we would also like to thank the owners BIMSA (Barcelona d'Infraestructures Municipals) and the Fundació Privada de l'Hospital de la Santa Creu i Sant Pau for allowing the use of their buildings and public structures in this research.

\section{References}

Barrias, A., Casas, J., \& Villalba, S. (2016). A Review of Distributed Optical Fiber Sensors for Civil Engineering Applications. Sensors, 16(5), 748. https://doi.org/10.3390/s16050748

Belal, M., \& Newson, T. P. (2011). A 5 cm spatial resolution temperature compensated distributed strain sensor evaluated using a temperature controlled strain rig. Optics 
Letters, 36(24), 4728-4730.

Billon, A., Henault, J.-M., Quiertant, M., Taillade, F., Khadour, A., Martin, R.-P., \& Benzarti, K. (2014). Quantitative strain measurements with distributed fiber optic systems: Qualification of a sensing cable bonded to the surface of a concrete structure. 7th European Workshop on Structural Health Monitoring, EWSHM 2014 - 2nd European Conference of the Prognostics and Health Management (PHM) Society.

Casas, J. R., \& Cruz, P. J. S. (2003). Fiber Optic Sensors for Bridge Monitoring. Journal of Bridge Engineering, 8(6), 362-373. https://doi.org/10.1061/(ASCE)1084-0702(2003)8:6(362)

Domaneschi, M., Sigurdardottir, D., \& Glišić, B. (2017). Damage detection on outputonly monitoring of dynamic curvature in composite decks. Structural Monitoring and Maintenance, 4(1), 1-15. https://doi.org/https://doi.org/10.12989/smm.2017.4.1.001

Farrar, C. R., \& Worden, K. (2007). An introduction to structural health monitoring. Philosophical Transactions. Series A, Mathematical, Physical, and Engineering Sciences, 365(1851), 303-315. https://doi.org/10.1098/rsta.2006.1928

Glisic, B., Hubbell, D., Sigurdardottir, D. H., \& Yao, Y. (2013). Damage detection and characterization using long-gauge and distributed fiber optic sensors. Optical Engineering, 52, 87101. https://doi.org/10.1117/12.2009817

Glisic, B., \& Inaudi, D. (2012). Development of method for in-service crack detection based on distributed fiber optic sensors. Structural Health Monitoring, 11(2), 161171. https://doi.org/10.1177/1475921711414233

Grave, J. H. L., Håheim, M. L., \& Echtermeyer, A. T. (2015). Measuring changing strain fi elds in composites with Distributed Fiber- Optic Sensing using the optical backscatter re fl ectometer. Composites Part B, 74, 138-146. https://doi.org/10.1016/j.compositesb.2015.01.003

Güemes, A., Fernández-López;, \& Soller, B. (2010). Optical Fiber Distributed Sensing - Physical Principles and Applications. Structural Health Monitoring. 
https://doi.org/10.1177/1475921710365263

Henault, J.-M., Moreau, G., Blairon, S., Salin, J., Courivaud, J.-R., Taillade, F., ... Delepine-Lesoille, S. (2010). Truly Distributed Optical Fiber Sensors for Structural Health Monitoring: From the Telecommunication Optical Fiber Drawling Tower to Water Leakage Detection in Dikes and Concrete Structure Strain Monitoring. Advances in Civil Engineering, 2010, 1-13. https://doi.org/10.1155/2010/930796

Lopez-Higuera, J. M., Rodriguez Cobo, L., Quintela Incera, A., \& Cobo, A. (2011).

Fiber Optic Sensors in Structural Health Monitoring. Journal of Lightwave Technology, 29(4), 587-608. https://doi.org/10.1109/JLT.2011.2106479

LUNA, I. I. (2012). Optical Backscatter Reflectometer (Model OBR 4600). [Online]. Retrieved February 1, 2017, from http://lunainc.com/wpcontent/uploads/\%0A2012/11/NEW-OBR4600_Data-Sheet_Rev-04.pdf

LUNA, I. I. (2014). Distributed Fiber Optic Sensing: Temperature Compensation of Strain Measurement Contents.

LUNA, I. I. (2017). ODiSI Fiber Optic Sensor Installation Guide. Retrieved from https://lunainc.com/wp-content/uploads/2017/01/TN_Applying-StrainSensors_RevB_v1.pdf

Mayhew, H. E., Frano, K. A., Svoboda, S. A., \& Wustholz, K. L. (2014). Using Raman Spectroscopy and Surface-Enhanced Raman Scattering To Identify Colorants in Art: An Experiment for an Upper-Division Chemistry Laboratory. Journal of Chemical Education, 92(1), 148-152.

Muehlethaler, C., Leona, M., \& Lombardi, J. R. (2015). Review of surface enhanced Raman scattering applications in forensic science. Analytical Chemistry, 88(1), 152-169.

Palmieri, L., \& Schenato, L. (2013). Distributed Optical Fiber Sensing Based on Rayleigh Scattering. The Open Optics Journal, 7(1), 104-127.

Regier, R., \& Hoult, N. a. (2014). Distributed Strain Behavior of a Reinforced Concrete Bridge: Case Study. Journal of Bridge Engineering, 19(12), 5014007. 
https://doi.org/10.1061/(ASCE)BE.1943-5592.0000637

Rodriguez, G., Casas, J. R. ., \& Villalba, S. (2015). SHM by DOFS in civil engineering: a review. Structural Monitoring and Maintenance, 2(4), 357-382. https://doi.org/10.12989/smm.2015.2.4.357

Rodríguez, G., Casas, J. R., \& Villaba, S. (2015). Cracking assessment in concrete structures by distributed optical fiber. Smart Materials and Structures, 24(3), 35005.

Rodriguez, G., Casas, J. R., \& Villalba, S. (2014). Assessing Cracking Characteristics of Concrete Structures by Distributed Optical Fiber and Non-Linear Finite Element Modelling To cite this version : In 7th European Workshop on Structural Health Monitoring. Nantes.

Samiec, D. (2012). Distributed fibre-optic temperature and strain measurement with extremely high spatial resolution. Photonik International.

Shen, S., Wu, Z., Yang, C., Wan, C., Tang, Y., \& Wu, G. (2010). An improved conjugated beam method for deformation monitoring with a distributed sensitive fiber optic sensor. Structural Health Monitoring, 9(4), 361-378.

Todd, M. D., Johnson, G. A., \& Vohra, S. T. (2001). Deployment of a fiber Bragg grating-based measurement system in a structural health monitoring application. Smart Materials and Structures, 10(3), 534.

Uchida, S., Levenberg, E., \& Klar, A. (2015). On-specimen strain measurement with fiber optic distributed sensing. Measurement, 60, 104-113.

Villalba, S., \& Casas, J. R. (2013). Application of optical fiber distributed sensing to health monitoring of concrete structures. Mechanical Systems and Signal Processing, 39(1), 441-451.

Villalba, V., Casas, J. R., \& Villalba, S. (2012). Application of OBR fiber optic technology in structural health monitoring of Can Fatjó Viaduct (Cerdanyola de Vallés-Spain). In VI International Conference on Bridge Maintenance, Safety and Management. Stresa, Italy. 
Wan, K. T., Leung, C. K. Y., \& Olson, N. G. (2008). Investigation of the strain transfer for surface-attached optical fiber strain sensors. Smart Materials and Structures, 17(3), 35037.

Ye, X. W., Su, Y. H., \& Han, J. P. (2014). Structural Health Monitoring of Civil Infrastructure Using Optical Fiber Sensing Technology: A Comprehensive Review. The Scientific World Journal, 2014, 652329. https://doi.org/10.1155/2014/652329 